\title{
DETERMINAÇÃO DA CONCENTRAÇÃO DE METAIS TRAÇO EM SEDIMENTOS DO ESTUÁRIO DO RIO MARACAÍPE - PE/BRASIL
}

\author{
COIMBRA, C.D.*; CARVALHO, G.; PHILIPPINI, H.; SILVA, M.F.M. \& NEIVA, E. \\ Associação Instituto Tecnológico de Pernambuco - ITEP/OS \\ ${ }^{*}$ Corresponding author: camiladcoimbra@yahoo.com.br
}

\begin{abstract}
Coimbra, C.D.; Carvalho, G.; Philippini, H.; Silva, M.F.M. \& Neiva, E., 2015. Determinação da concentração de metais traço em sedimentos do estuário do rio Maracaípe - PE/BRASIL. Braz. J. Aquat. Sci. Technol. 19(2). elSSN 1983-9057. DOI: 10.14210/bjast.v19n2. Maracaípe region, located at Pernambuco's south coast, is suffering an intense development, and in spite of being a very important area for the society and the ecosystem, Maracaípe's estuary region is not much studied by the scientific community, what influenced the realization of this study. Samples were collected on winter (July/11, August/11, May/12, July/12 and August/12) and summer (December/11, April/12, October/12 and November/12) seasons, on three different stations, on each riverside. Hydrological parameters such as $\mathrm{pH}$, salinity, transparency, temperature and disolved oxygen were analyzed with a multiparametric sounder, model YSI6600 V2-4, and compared with CONAMA 357/2005 Resolution. Sediments were collected with acrylic spatula, on a $10 \mathrm{~cm}$ depth, then dried naturally and sieved for concentration analysis of the trace metals $(\mathrm{Cr}, \mathrm{Mn}, \mathrm{Fe}, \mathrm{Ni}, \mathrm{Cu}, \mathrm{Zn}, \mathrm{Cd}, \mathrm{Pb})$ and organic matter. For metal concentrations an Inductively Coupled Plasma - Optic Emission Spectrometer (ICP-OES) was used and results were compared with international standards from United States Environmental Protection Agency (US-EPA) and Canadian Council of Ministers of the Environment (CCME). Results indicated that dissolved oxygen content at Maracaípe estuary is under legal limit, except for Station 1. Metal concentration registered show Cd (7,4 $\pm 1,5 \mathrm{mg} \cdot \mathrm{kg}-1)$ and $\mathrm{Pb}(358 \pm 63$ mg.kg-1) are over the CCME limits, which are 3,5 mg.kg-1 and 91,3 mg.kg-1 respectively. Fe (30534 \pm 7057 mg.kg-1) was also over the EPA limit, which is 17000 mg.kg-1. The results were used for a Principal Component Analysis, with the help of The Unscrambler 9.2, showing the correlation between all of the variables. The study concluded that Station 3 sediments are the most contemned of all other stations, and the high concentrations registered (over the legal limits) suggest the estuary's monitoring.
\end{abstract}

Keywords: Estuary, Ecosystems, Trace metals, Sediments.

\section{INTRODUÇÃO}

A poluição de recursos hídricos nos últimos anos tem levado ao estudo dos ecossistemas aquáticos costeiros, que são importantes para preservação e equilíbrio da vida. Os despejos industriais e urbanos lançados nestes ecossistemas têm sido objeto de discussão em todo mundo, pois provocam modificações ambientais, aumentando também a pressão sobre as áreas costeiras (Silva, 2010).

Dentre os contaminantes provenientes de descarga de efluentes industriais, urbanos e agrícolas, os metais traço se destacam por não serem biodegradáveis. Os metais introduzidos pelas atividades antrópicas, muitas vezes, excedem os aportes naturais, representando um risco para a saúde humana e dos animais (Tam \& Wong, 2000; Drummond \& Israelachvili, 2004; Luiz-Silva et al., 2006; Prieto et al., 2008).

A determinação de metais traço em sedimentos permite quantificar o estoque mobilizável de um determinado contaminante em um local específico e, assim, detectar o grau de con $\urcorner$ taminação a que os ecossistemas aquáticos estão expostos (Baird, 2002; Cotta et al., 2006).
A região de Maracaípe vem sofrendo um intenso processo de urbanização dos seus ecossistemas costeiros, promovendo o aparecimento de indicadores negativos, como emissão de efluentes domésticos e resíduos sólidos, aterros nos manguezais, entre outros (Vila Nova et al., 2009), justificando uma avaliação da contaminação por metais traço no local.

Diante do exposto, o objetivo do trabalho foi avaliar as concentrações de metais traço em sedimentos coletados no estuário do rio Maracaípe - PE, determinando suas variações sazonais e o grau de impacto no ecossistema, de modo a fornecer subsídios para estabelecer um sistema de monitoramento ambiental na área.

\section{MATERIAIS E MÉTODOS}

\section{Descrição da área de estudo}

O estuário do rio Maracaípe está localizado no município de Ipojuca, litoral sul do Estado de Pernambuco, a $52 \mathrm{~km}$ da cidade do Recife, entre as coordenadas $08^{\circ} 23^{\prime} 56^{\prime \prime} S$ e $35^{\circ} 03^{\prime} 50^{\prime \prime} \mathrm{W}$. O estuário vem sofrendo processo de urbanização bastante acelerado evidenciado por Vila Nova \& Torres (2012) 
quando observaram a vegetação de mangue e restinga existente no estuário e verificaram que na última década houve redução de aproximadamente 16,59\% e $52,81 \%$, respectivamente, em detrimento da urbanização, que aumentou 247,01\% entre 1989 e 2011.

\section{Amostragens}

Os sedimentos foram coletados em três estações, tendo sido realizadas coletas nas margens direita e esquerda de cada estação, totalizando seis amostras por coleta (Figura 1).
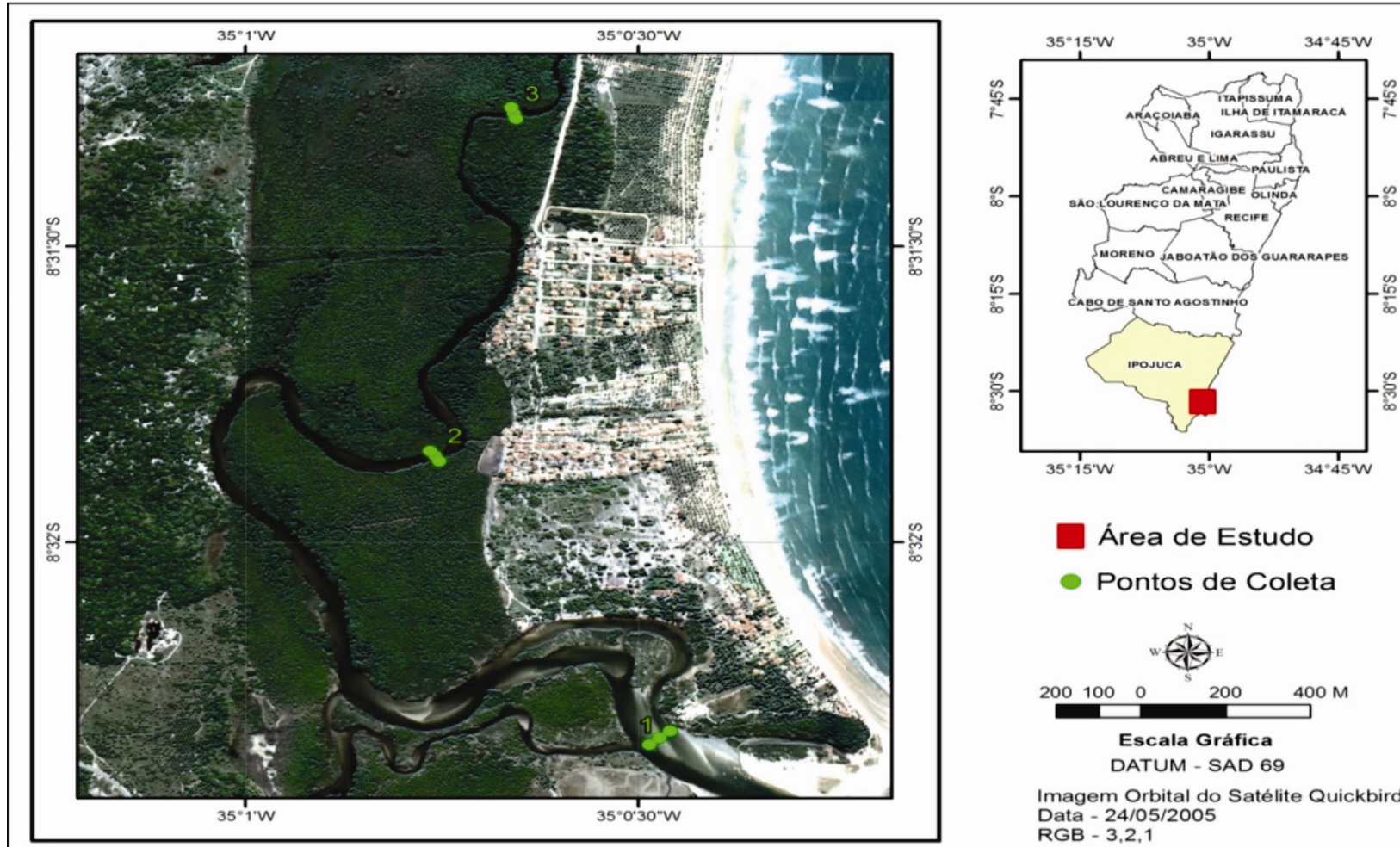

Área de Estudo

Pontos de Coleta

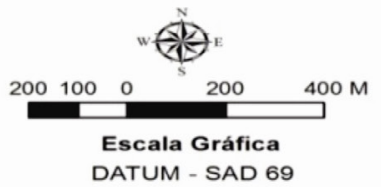

Imagem Orbital do Satélite Quickbird Data - 24/05/2005

RGB - 3,2,1

Figura 1 - Estações de coleta no estuário do rio Maracaípe.

\section{Coleta de parâmetros hidrológicos}

Os parâmetros hidrológicos foram analisados in situ conforme recomendação do Standard Methods for Examination of Water and Wastewater (APHA, 2012) na área de maior circulação estuarina, entre as estações de coleta de sedimentos, durante as baixa-mares.

A transparência da água foi medida utilizando Disco de Secchi com $30 \mathrm{~cm}$ de diâmetro. A temperatura, salinidade, o pH e o oxigênio dissolvido (OD) foram medidos utilizando-se uma Sonda Multiparamétrica Modelo YSI6600 V2-4.As taxas de saturação de oxigênio calculadas correlacionando-se os dados de oxigênio dissolvido com a temperatura e salinidade através da International Oceanographic Tables (Institute of Oceanography of Great Britain, 1973).

\section{Avaliação do percentual de matéria orgânica em sedimentos}

O percentual de matéria orgânica presente nos sedimentos coletados foi determinado através do método descrito em Manual de Métodos de Análise de Solos (Embrapa, 1997).

\section{Determinação da concentração de metais traço}

As amostras de sedimento foram secas em temperatura ambiente; destorroadas e peneiradas em malha de 60 micra para separação da fração fina.

Para abertura ácida das amostras foi utilizado o método $N^{\circ} 3050 B$, descrito pela Environmental Protection Agency (EPA) dos Estados Unidos. A digestão ácida dos sedimentos foi realizada em um digestor de amostras por micro-ondas, modelo Milestone Ethos One.

Para determinação dos metais $\mathrm{Cd}, \mathrm{Cu}, \mathrm{Pb}$, $\mathrm{Cr}, \mathrm{Fe}, \mathrm{Ni}, \mathrm{Mn}$ e $\mathrm{Zn}$ foi utilizado o Espectrômetro de Emissão Ótica com Plasma Indutivamente Acoplado (ICP-OES) da SPECTRO modelo Ciros.

\section{Avaliação do grau de impacto}

As concentrações dos metais traço analisados foram comparadas aos valores-guia definidos pelo Canadian Council of The Ministers of Environment (CCME), EPA e de background encontrados em estuário tropical, onde praticamente inexiste atividade antrópica, na Região Metropolitana do Recife (Rádio Pina). Os valores estão ilustrados na Tabela 1. 
Tabela 1 - Valores-guia do CCME, EPA e background

\begin{tabular}{|c|c|c|c|c|c|}
\hline \multirow[b]{2}{*}{ Elemento } & \multirow[b]{2}{*}{ Grupo quimico } & \multicolumn{4}{|c|}{ Concentração (mg.kg-1) } \\
\hline & & ISQG & PEL & EPA & $\begin{array}{l}\text { Background } \\
\text { (Rádio Pina) }\end{array}$ \\
\hline Cádmio & Inorgânico & 0,6 & 3,5 & - & - \\
\hline Cromo & Inorgânico & 37,3 & 90,0 & - & - \\
\hline Cobre & Inorgânico & 35,7 & 197,0 & - & - \\
\hline Chumbo & Inorgânico & 35,0 & 91,3 & - & - \\
\hline Zinco & Inorgânico & 123,0 & 315,0 & - & - \\
\hline Manganês & Inorgânico & - & - & & 160 \\
\hline Ferro & Inorgânico & - & - & 17.000 & - \\
\hline
\end{tabular}

\section{Análise de componentes principais}

Para análise de correlação entre as concentrações de metais e parâmetros hidrológicos nas estações avaliadas, foi utilizado o programa The Unscrambler versão 9.7 .

\section{RESULTADOS}

\section{Análise de componentes principais (ACP)}

A matriz dos dados foi composta por 16 parâmetros e 54 amostras. Analisando três componentes principais para cada estação, obtiveram-se percentuais de explicação dos resultados de $67 \%$,
$67 \%$ e $65 \%$, nas estações 1, 2 e 3 respectivamente. 0 percentual de explicação exprime a correlação entre os resultados dos diversos parâmetros analisados numa determinada estação.

\section{Estação 1}

Na Figura 2 está representada a matriz de amostras da estação 1, relacionando a Componente principal 1 (CP1) e a Componente principal 2 (CP2). Na Figura 3 está representada a matriz de parâmetros, relacionando também CP1 e CP2. No eixo CP1, à esquerda, observa-se amostra de Out/12 ME, característica do período seco, que apresenta baixas concentrações dos metais $\mathrm{Cd}, \mathrm{Pb}, \mathrm{Fe}, \mathrm{Ni}, \mathrm{Zn}$ e $\mathrm{Cr}$.

No eixo da CP2, escores positivos, pode-se verificar as amostras de Dez/11 (período seco), associadas à valores mais elevados de salinidade, condutividade, transparência e $\mathrm{pH}$. Já nos escores negativos, é possível encontrar amostras de Mai/12, correlacionadas à baixas concentrações de M.O., saturação de $\mathrm{O} 2$ e O.D.

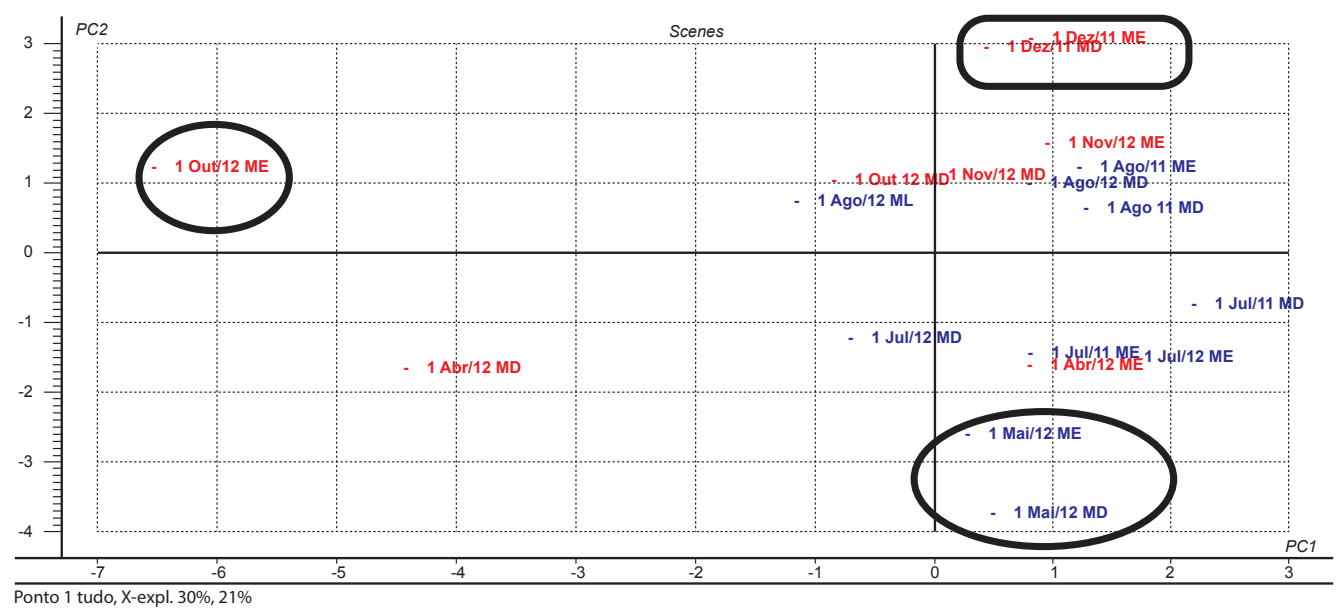

Figura 2 - Matriz CP1 e CP2 (amostras) da estação 1

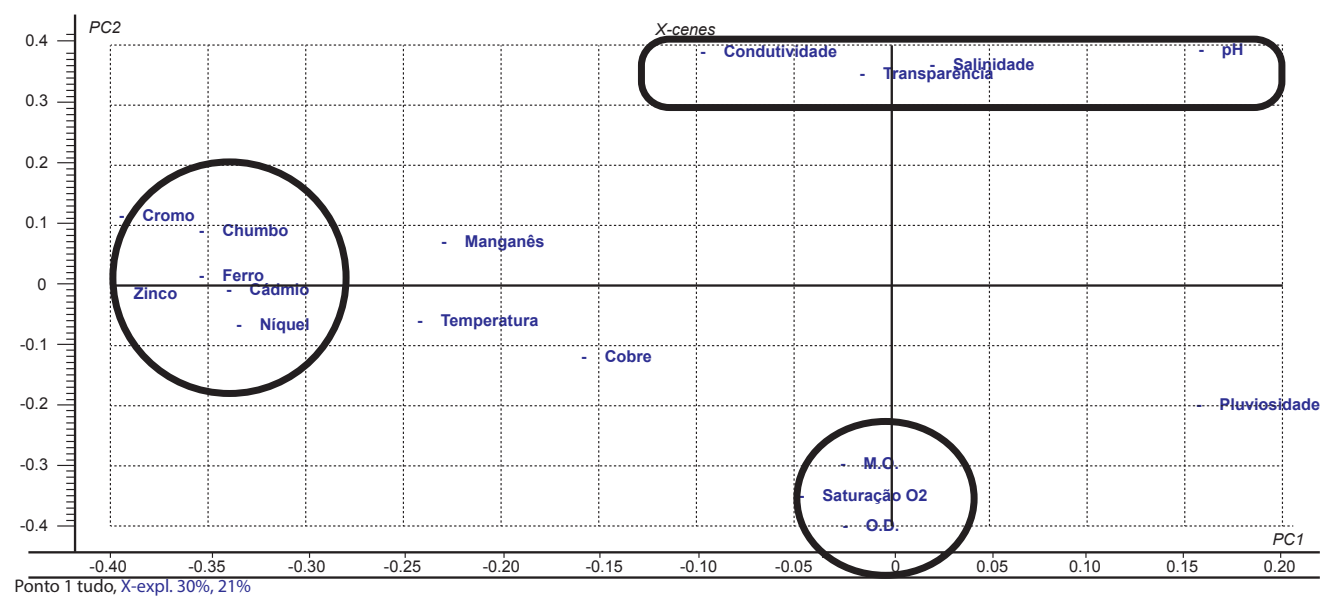

Figura 3 - Matriz CP1 e CP2 (parâmetros) da estação 1 
Na Figura 4 está representada a matriz de amostras da estação 1, relacionando a CP1 e a CP3. Na Figura 5 está representada a matriz de parâmetros, relacionando também CP1 e CP3.

Nos escores positivos do eixo CP3, estão apresentadas amostras de Abr/12 ME, Mai/12 MD, e Nov/12 associadas à saturação de O2, O.D., transparência e salinidade. Nos escores negativos, evidencia-se amostras de Jul/11 relacionadas com alta pluviosidade.

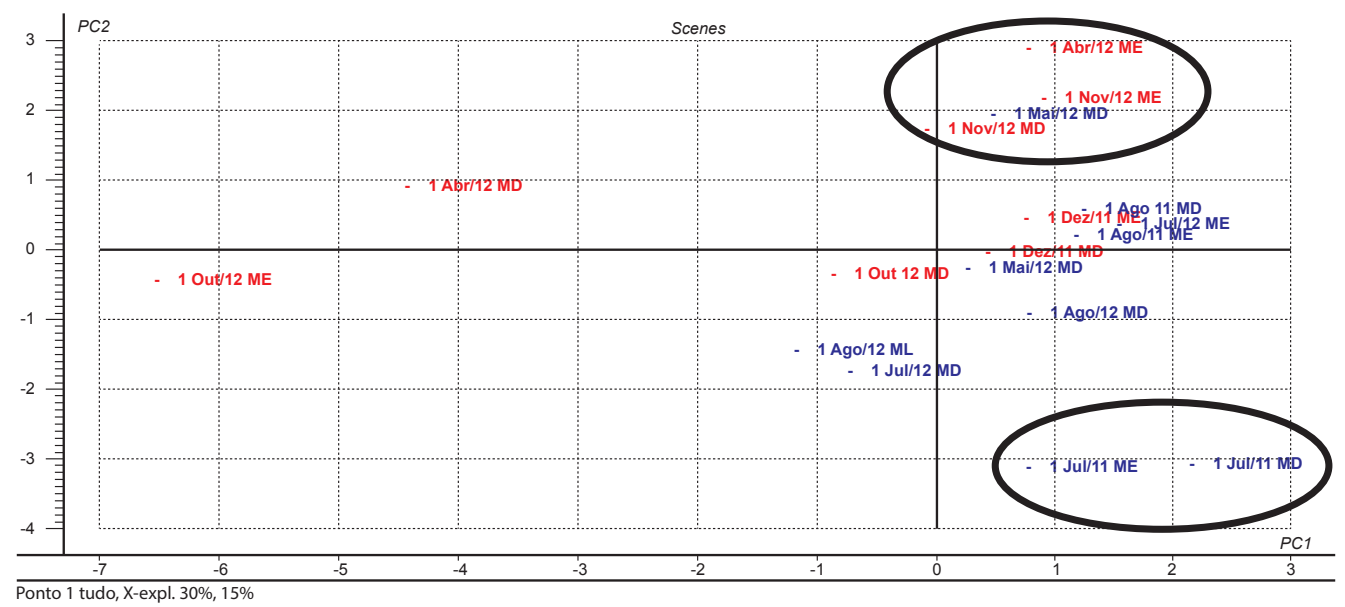

Figura 4 - Matriz CP1 e CP3 (amostras) da estação 1

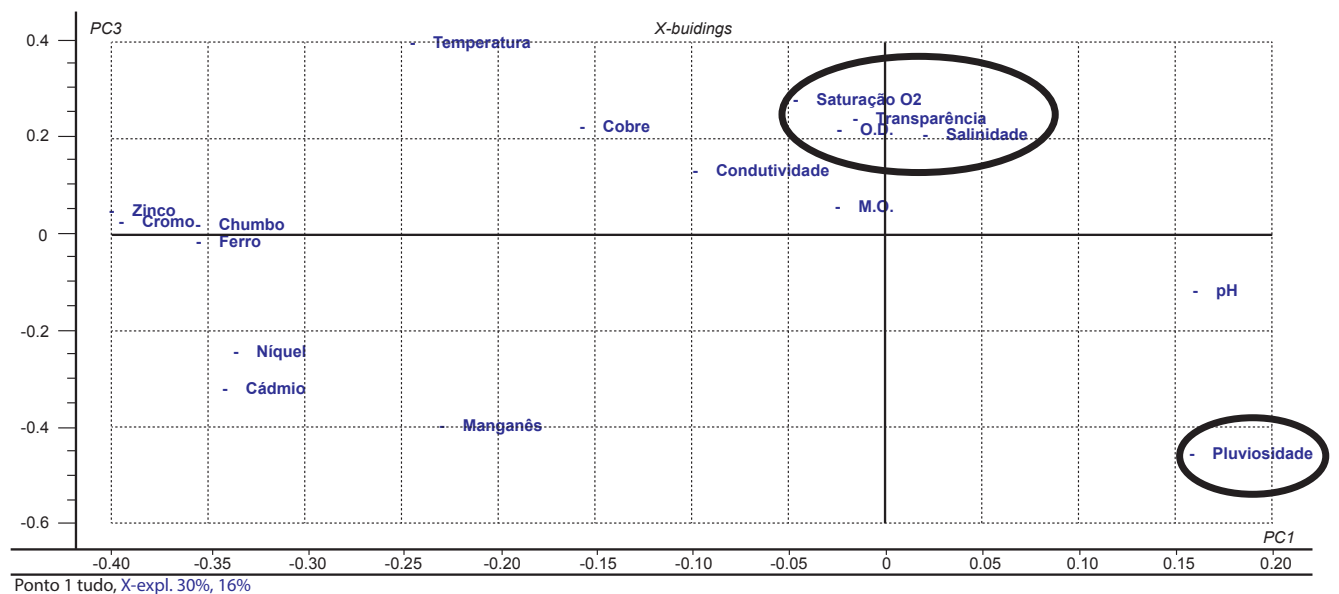

Figura 5 - Matriz CP1 e CP3 (parâmetros) da estação 1

\section{Estação 2}

Na Figura 6 está representada a matriz de amostras da estação 2, relacionando a CP1 e a CP2. Na Figura 7 está representada a matriz de parâmetros, relacionando também $\mathrm{CP} 1$ e CP2.

$\mathrm{Na} \mathrm{CP} 1$, à direita, observa-se amostras de Abr/12, Out/12 e Nov/12, apontando para menores concentrações de $\mathrm{Pb}, \mathrm{Cd}, \mathrm{Cu}, \mathrm{Cr}, \mathrm{Fe}, \mathrm{Mn}, \mathrm{Zn}$ e altas temperaturas e teor de M.O. Ainda na CP1, à esquerda, encontra-se amostras de Jul/11 MD, associadas à pluviosidade.

$\mathrm{Na} \mathrm{CP} 2$, nos escores negativos, encontram-se amostras de Ago/12, apontando para maiores teores de O.D. e saturação de O2. Já nos escores positivos, a amostra de Dez/11 está relacionada com altas concentrações de $\mathrm{Ni}$, e alta transparência.

Na Figura 8 está representada a matriz de amostras da estação 1, relacionando a CP1 e a CP3. Na Figura 9 está representada a matriz de parâmetros, relacionando também $\mathrm{CP} 1$ e $\mathrm{CP} 3$.

$\mathrm{Na}$ análise da CP3, observa-se nos escores positivos, amostras de Dez/11 associadas à altos valores de $\mathrm{pH}$ e salinidade. Nos escores negativos, amostra de Jul/12 ME associadas a alta concentração de níquel. 
Braz. J. Aquat. Sci. Technol., 2015, 19(2).

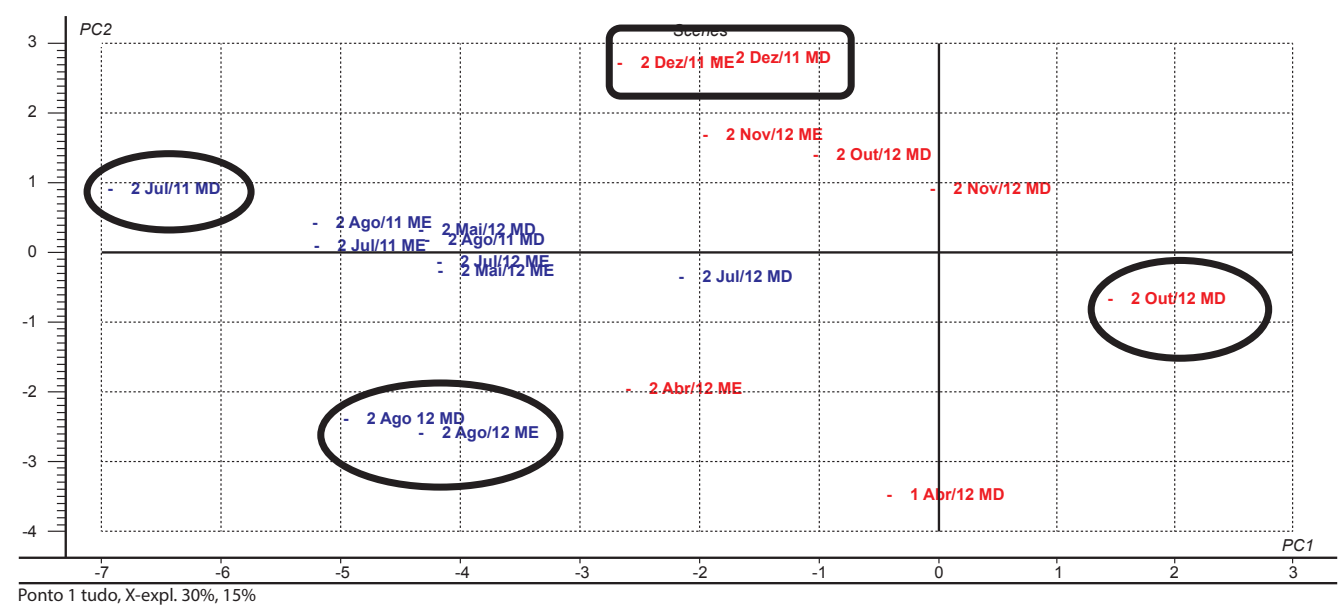

Figura 6 - Matriz CP1 e CP2 (amostras) da estação 2

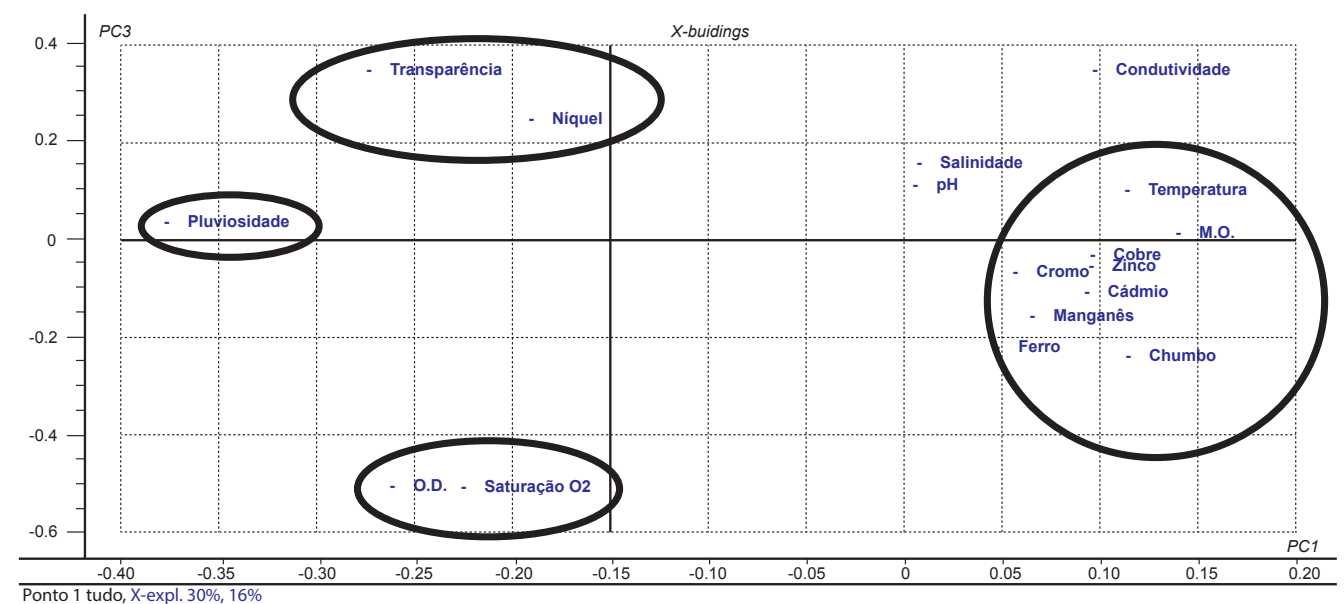

Figura 7 - Matriz CP1 e CP2 (parâmetros) da estação 2

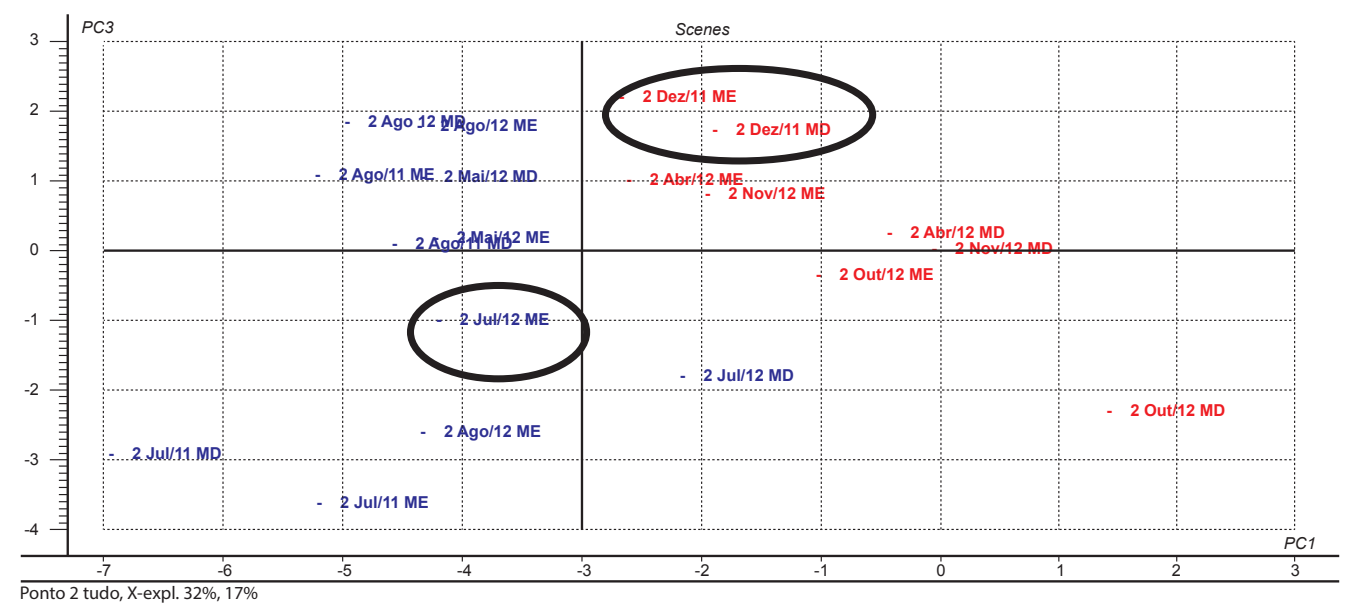

Figura 8 - Matriz CP1 e CP3 (amostras) da estação 2 


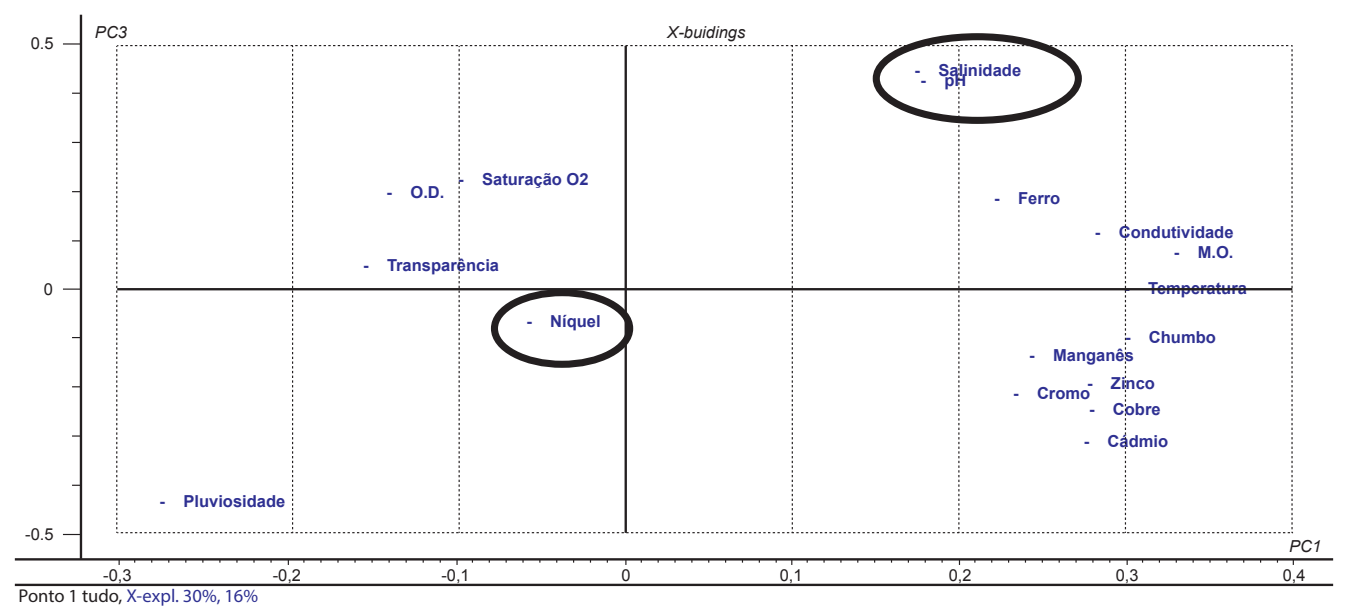

Figura 9 - Matriz CP1 e CP3 (parâmetros) da estação 2

\section{Estação 3}

Na Figura 10 está representada a matriz de amostras da estação 3, relacionando a CP1 e a CP2. Na Figura 11 está representada a matriz de parâmetros, relacionando também CP1 e CP2.

$\mathrm{Na} \mathrm{CP} 1$, nos quadrantes positivos, à direita, evidenciam-se associações entre as amostras de Abr/12 MD e Out/12 com altos teores de Cr, Cd, Ni, $\mathrm{Mn}$ e $\mathrm{Cu}$. Ainda na $\mathrm{CP} 1$, à esquerda, observa-se amostra de Ago/12 MD localizada no escore oposto, evidenciando alta pluviosidade, e altos teores de O.D. e saturação.
Avaliando a CP2, nos escores positivos, observa-se amostras de Dez/11 e Nov/12 relacionadas à altos valores de M.O., temperatura, salinidade e condutividade.

Na Figura 12 está representada a matriz de amostras da estação 3, relacionando a CP1 e a CP3. Na Figura 13 está representada a matriz de parâmetros, relacionando também CP1 e CP3.

$\mathrm{Na} \mathrm{CP} 3$, escores positivos, verifica-se a presença de amostra de Ago/12 ME associada a altos valores de transparência e salinidade.

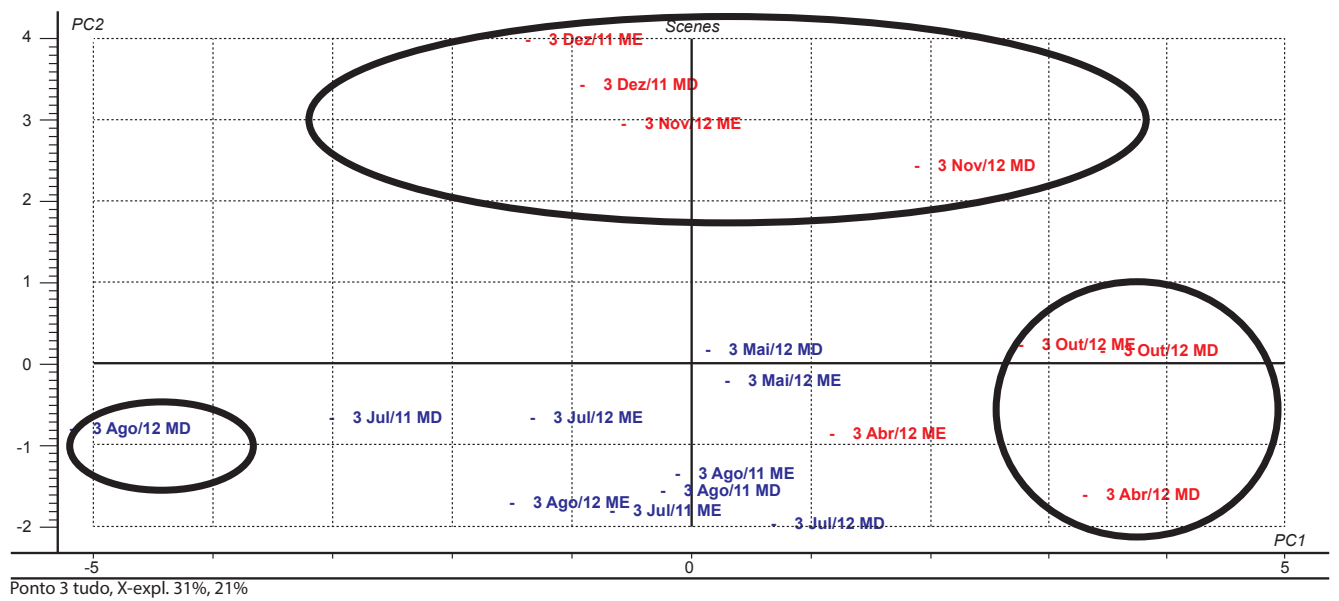

Figura 10 - Matriz CP1 e CP2 (amostras) da estação 3 


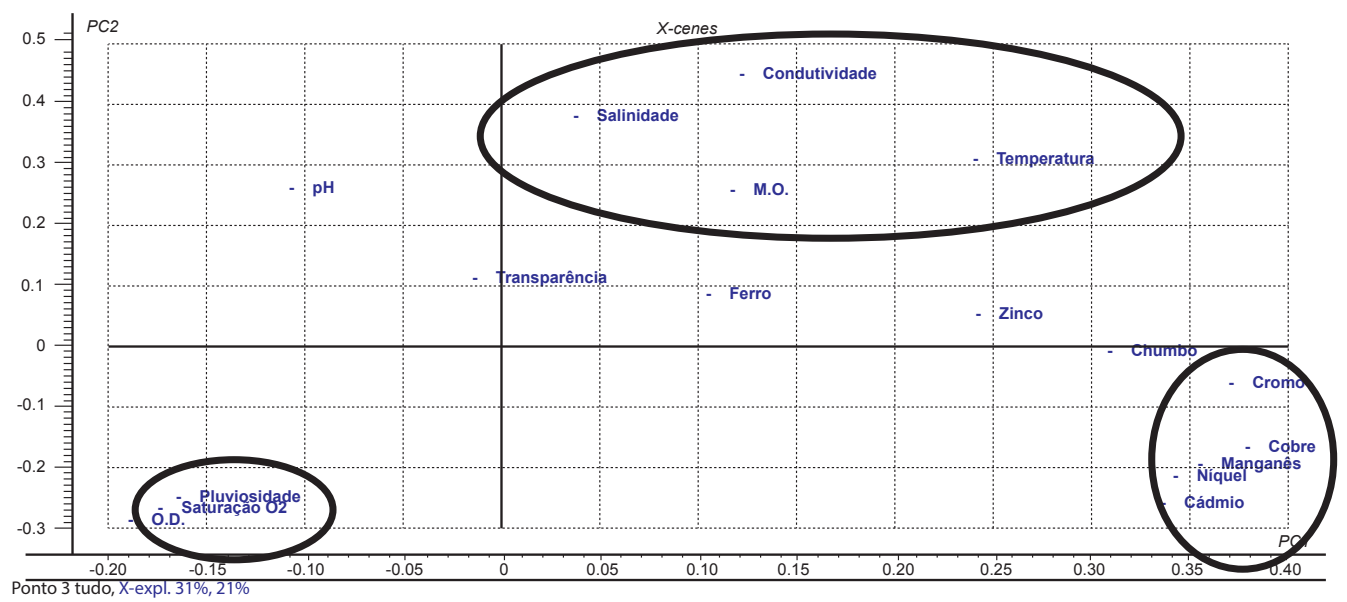

Figura 11 - Matriz CP1 e CP2 (parâmetros) da estação 3

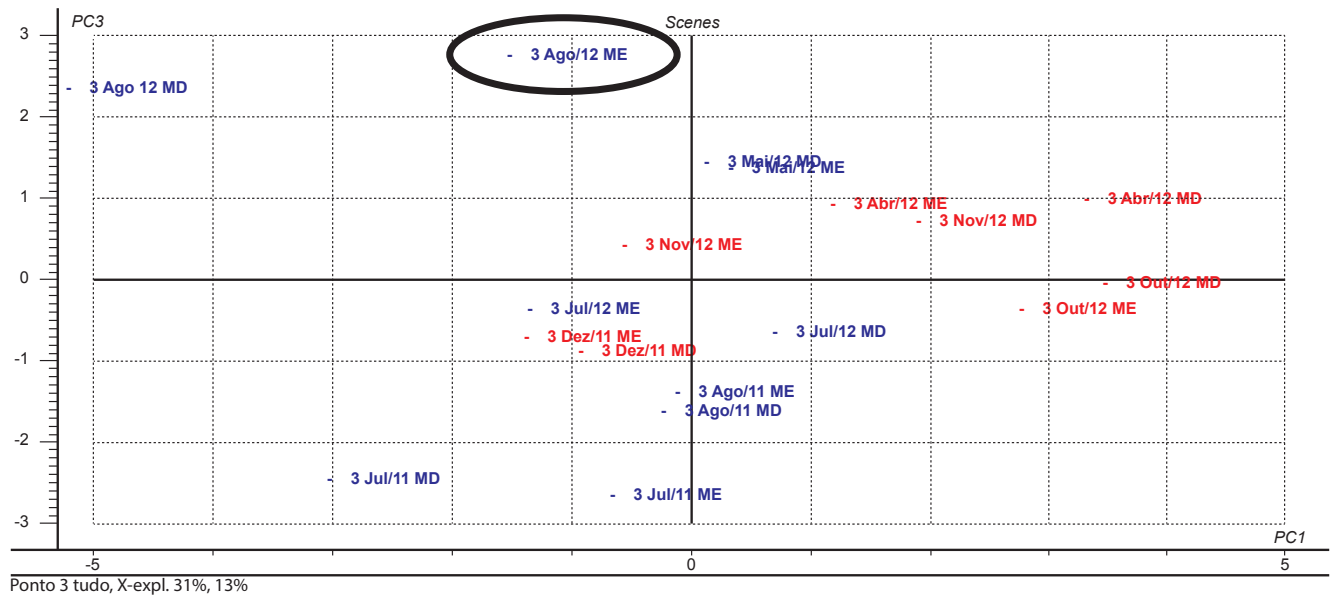

Figura 12 - Matriz CP1 e CP3 (amostras) da estação 3

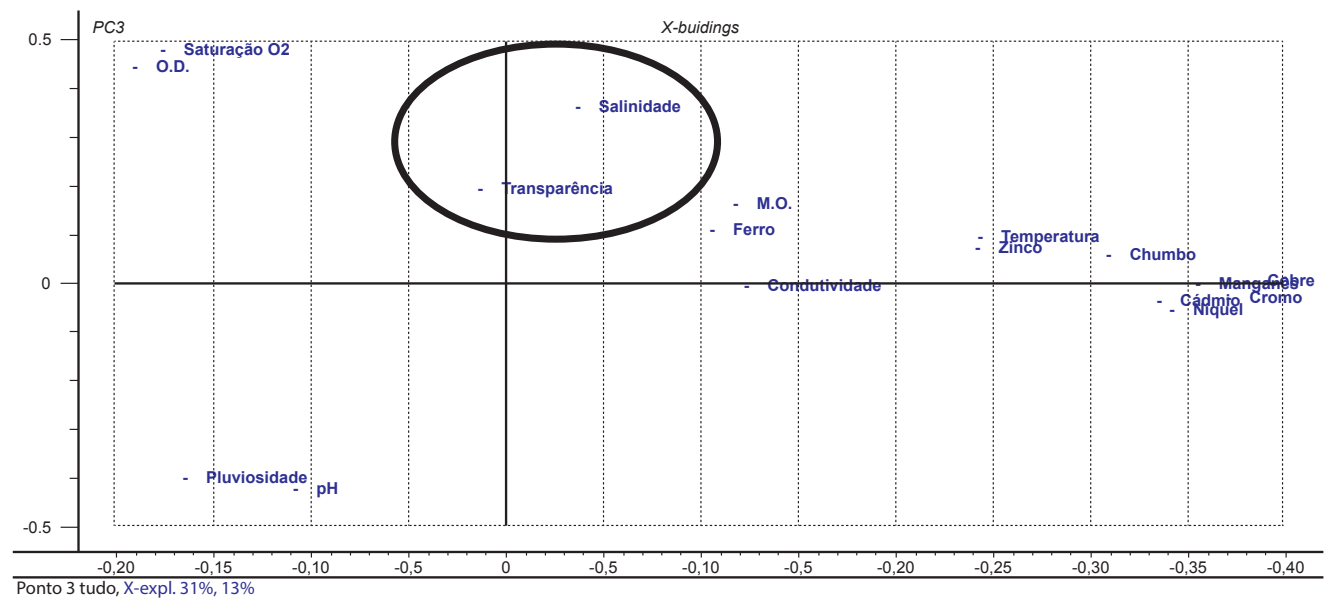

Figura 13 - Matriz CP1 e CP3 (parâmetros) da estação 3 


\section{Avaliação de parâmetros hidrológicos}

Os resultados hidrológicos de $\mathrm{pH}$, temperatura, Salinidade, Oxigênio Dissolvido e transparência podem ser observados nas Figuras de 14 a 18.
Metais

Os resultados dos metais $\mathrm{Cd}, \mathrm{Pb}, \mathrm{Cu}, \mathrm{Cr}, \mathrm{Fe}$, $\mathrm{Mn}, \mathrm{Ni}$ e $\mathrm{Zn}$ estão representados nas Figuras de 20 a 27.

\section{Avaliação de sedimentos}

\section{Percentual de matéria orgânica}

Os percentuais de matéria orgânica encontrados nos sedimentos coletados estão apresentados na Figura 19.

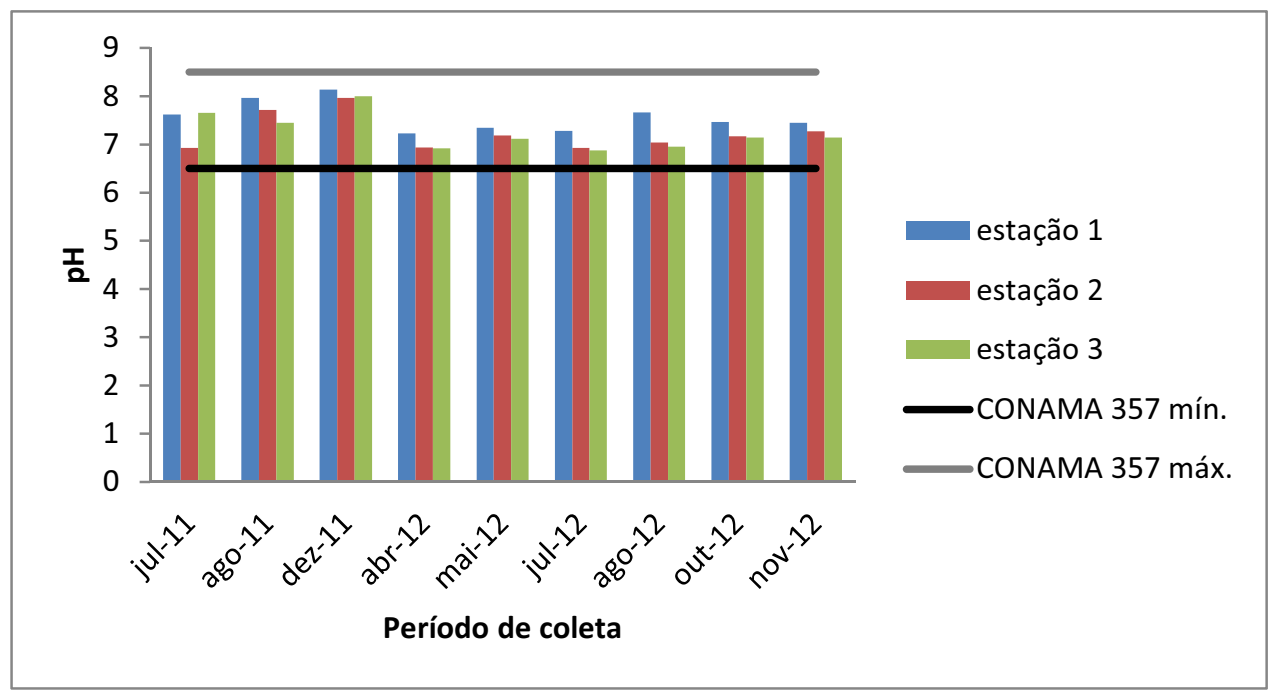

Figura $14-\mathrm{pH}$ da água nas estações de coleta

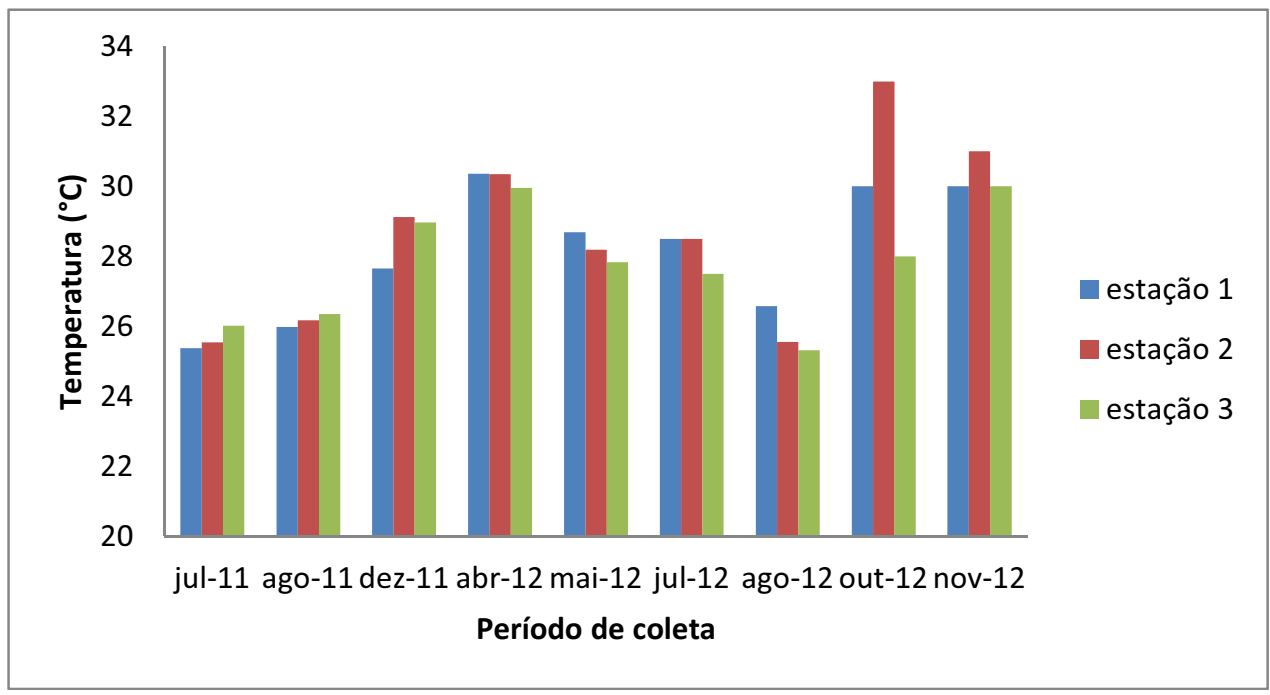

Figura 15 - Temperaturas da água nos estações de coleta 


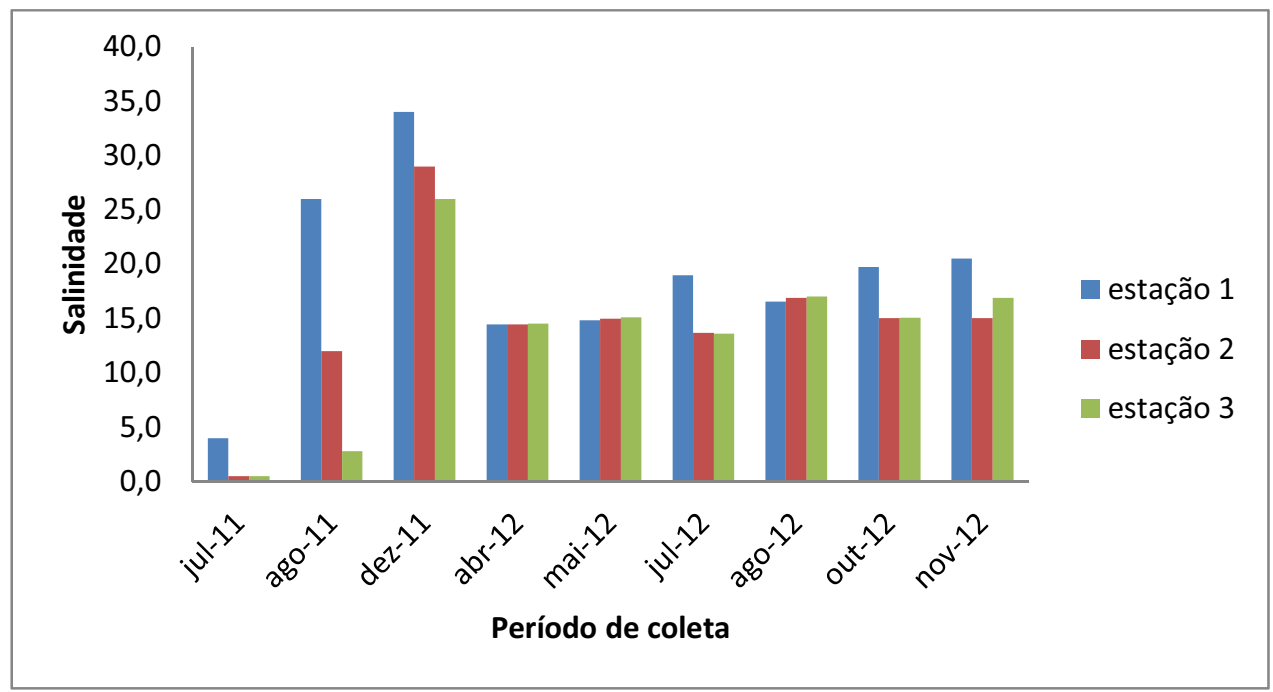

Figura 16 - Salinidade da água nas estações de coleta

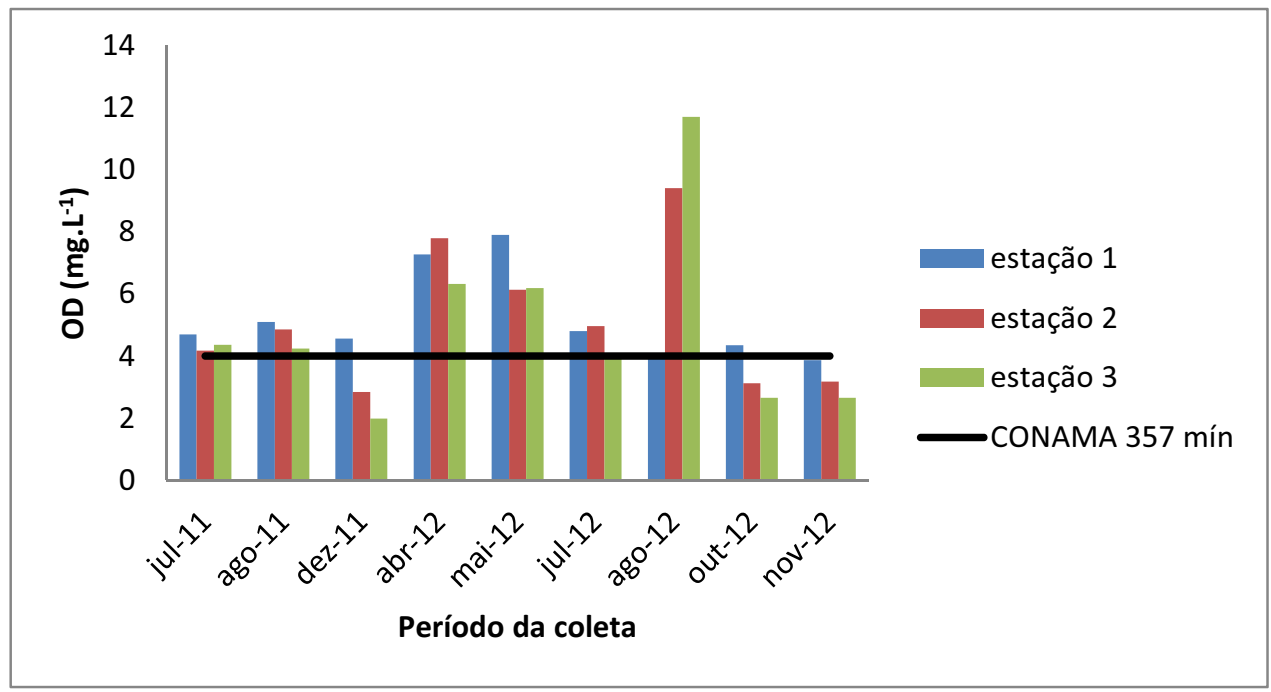

Figura 17 - Teor de oxigênio dissolvido na água nas estações de coleta

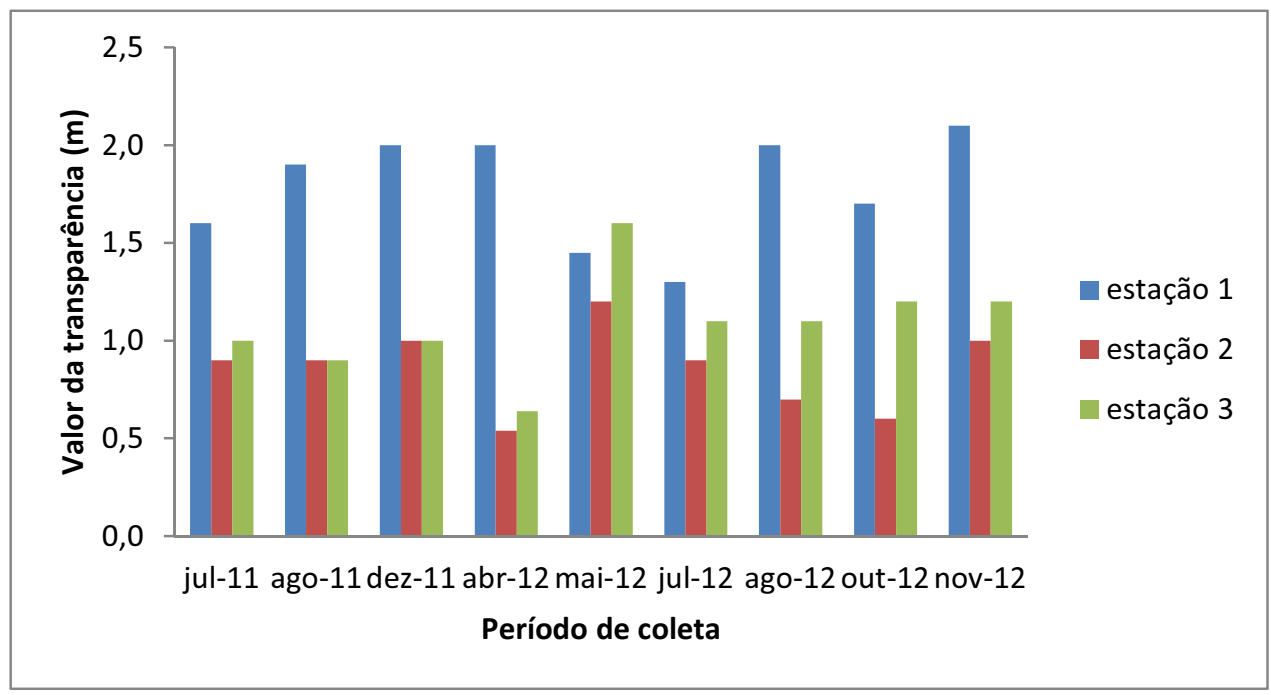

Figura 18-Transparência da água nas estações de coleta 


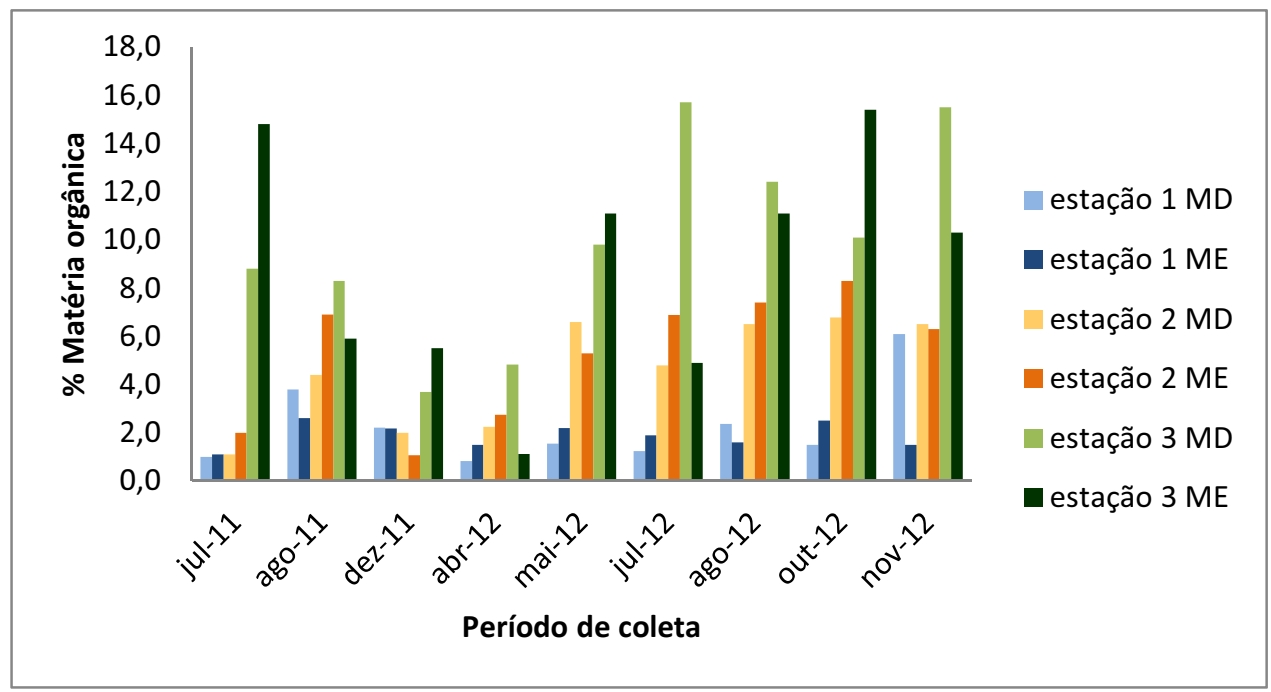

Figura 19 - Percentuais de matéria orgânica nos sedimentos coletados

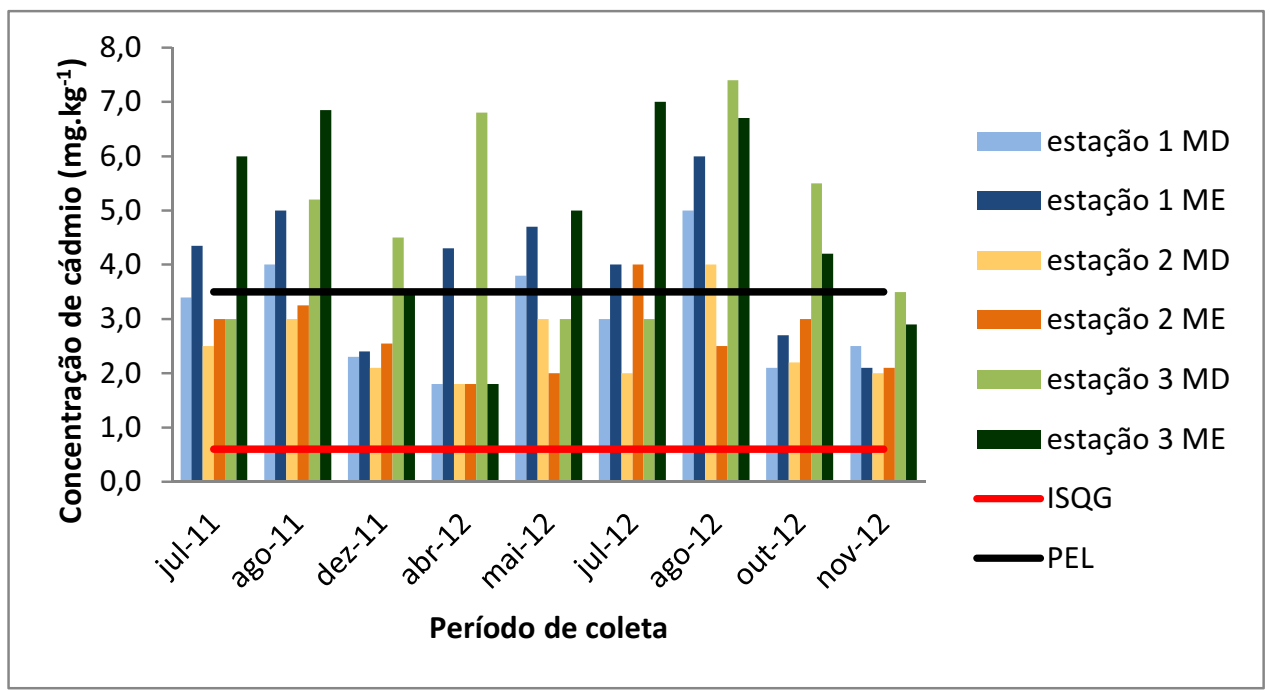

Figura 20 - Concentrações de cádmio nos sedimentos coletados

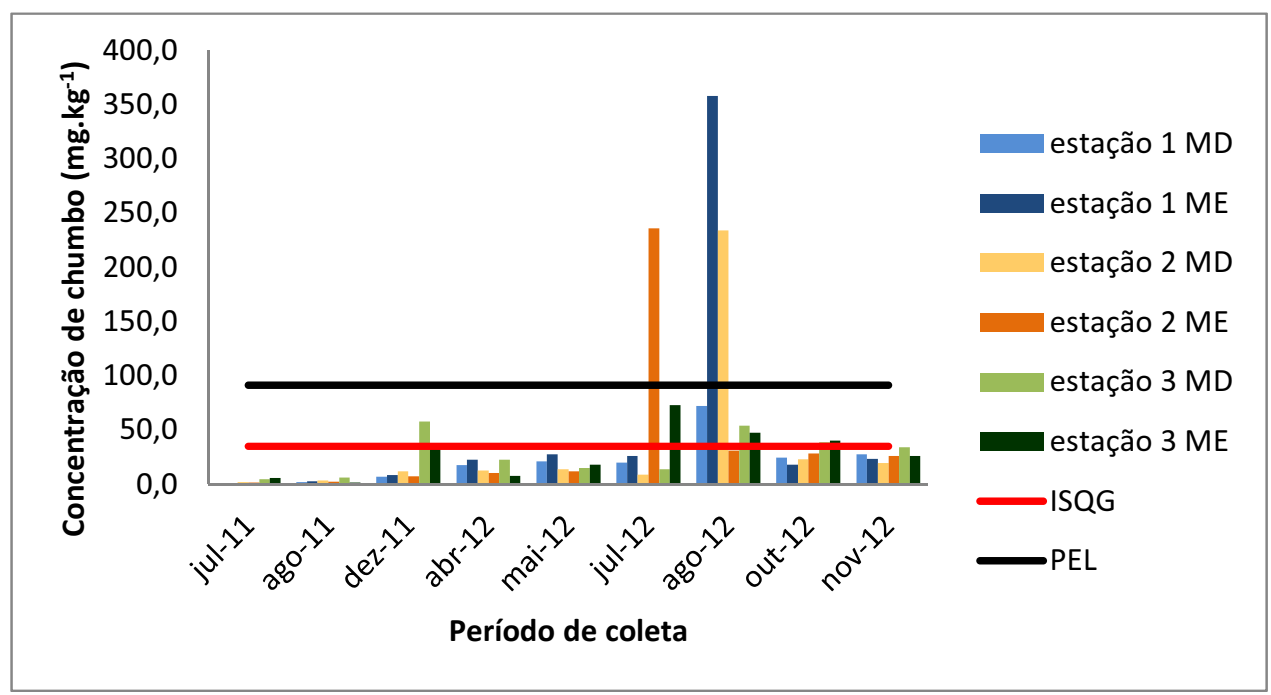

Figura 21 - Concentrações de chumbo nos sedimentos coletados 


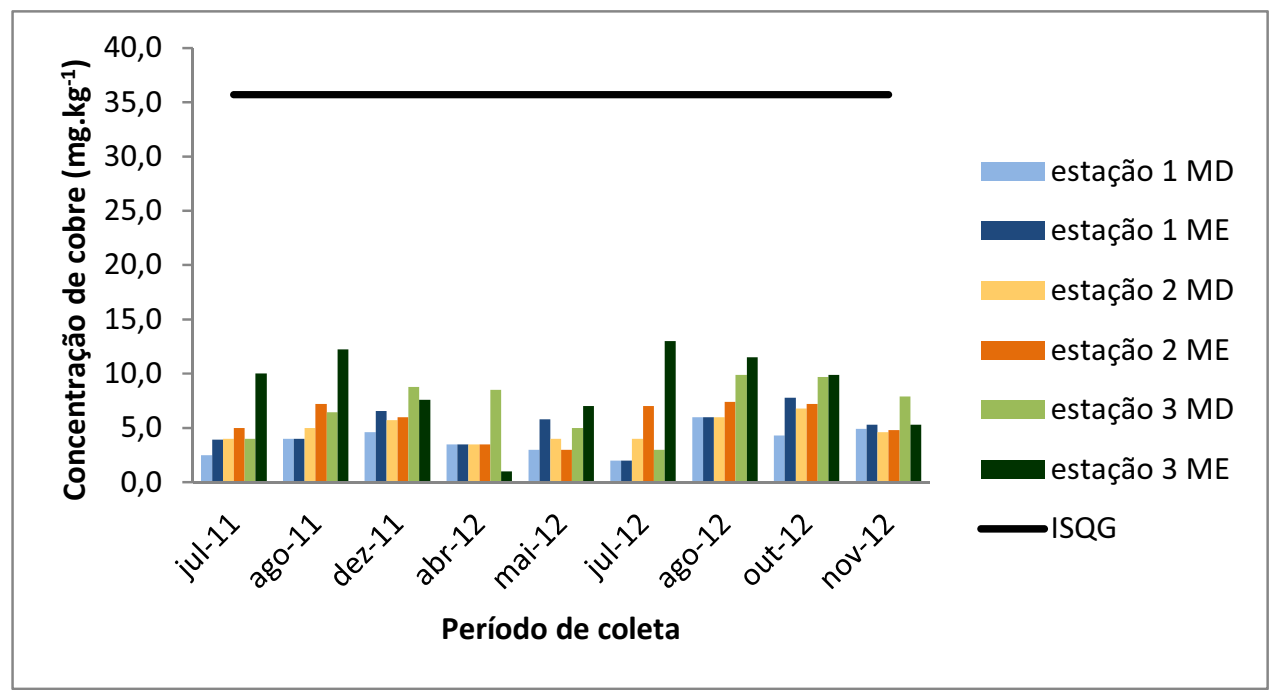

Figura 22 - Concentrações de cobre nos sedimentos coletados

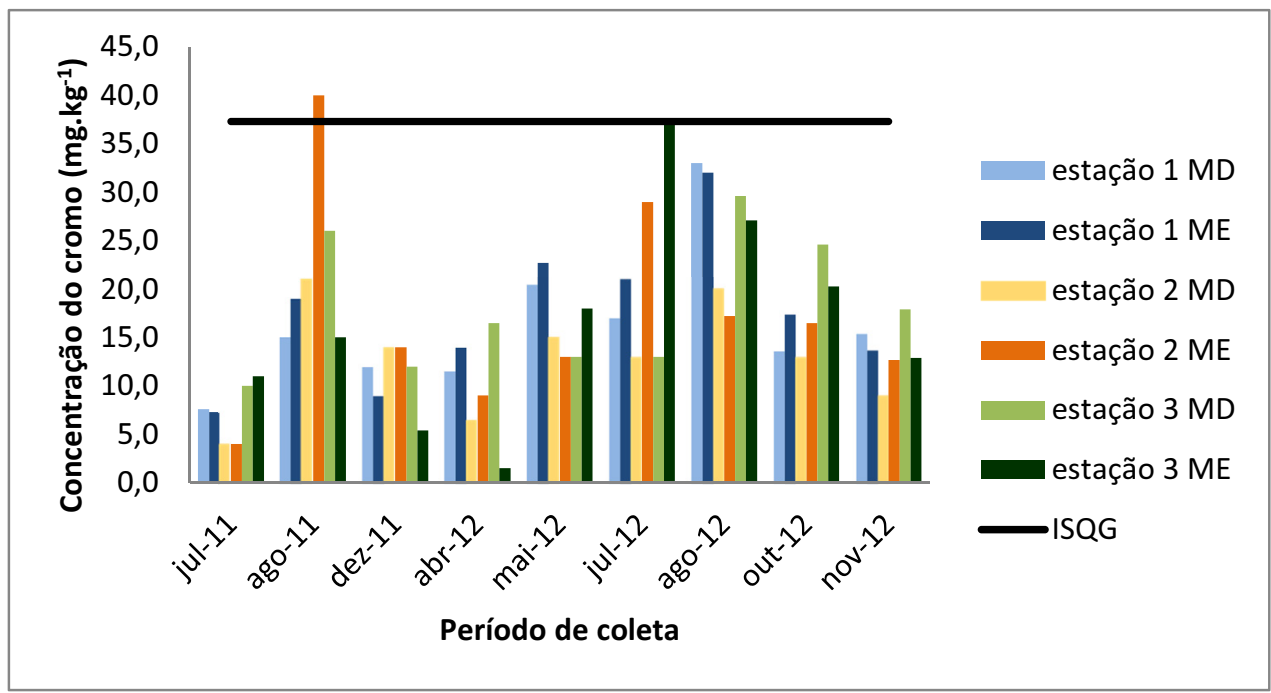

Figura 23 - Concentrações de cromo nos sedimentos coletados

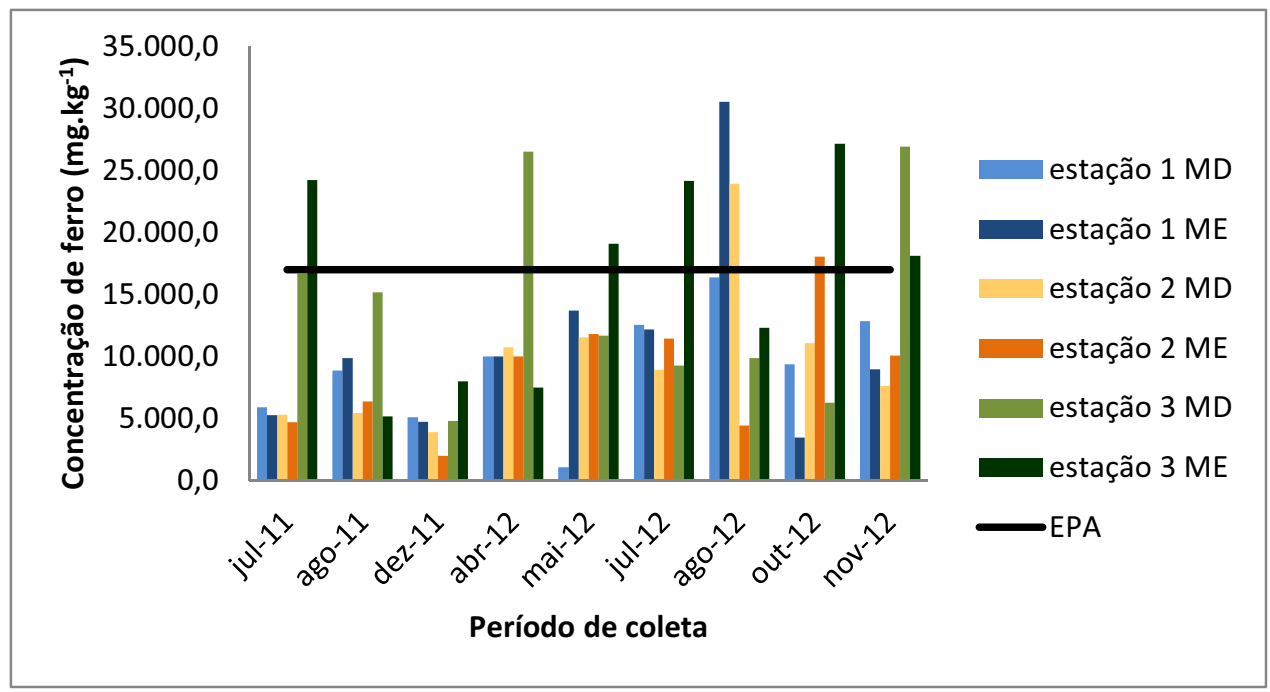

Figura 24 - Concentrações de ferro nos sedimentos coletados 


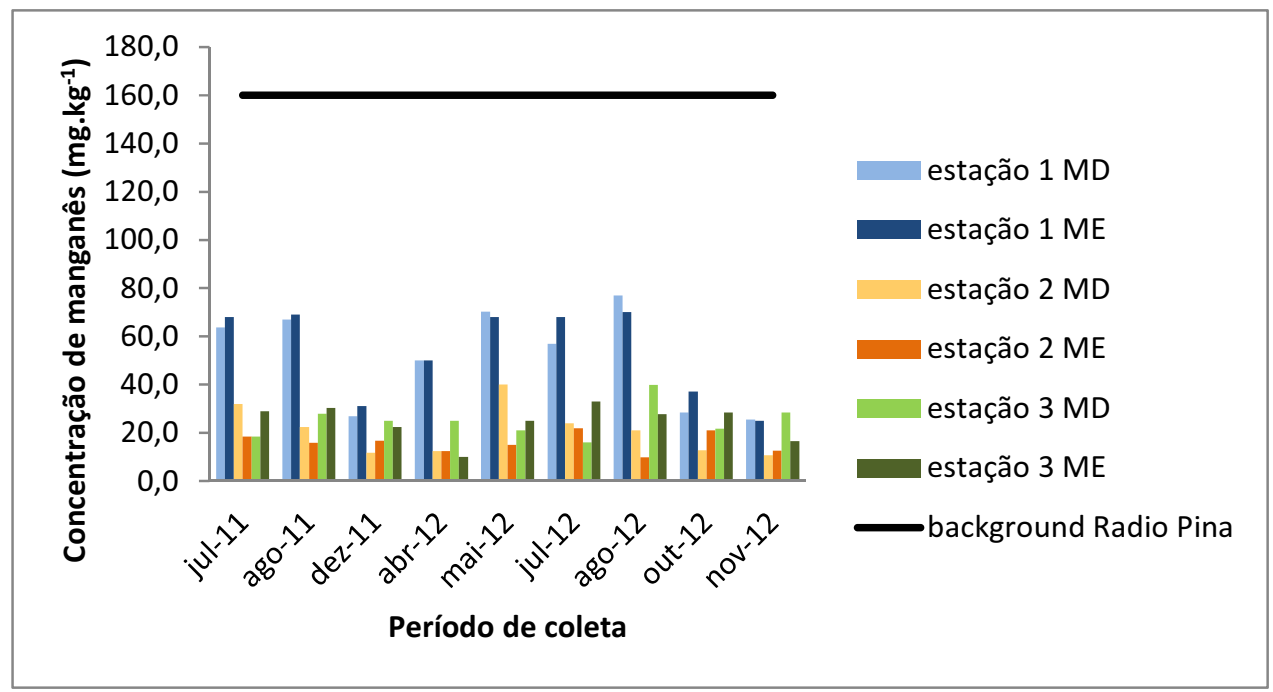

Figura 25 - Concentrações de manganês nos sedimentos coletados

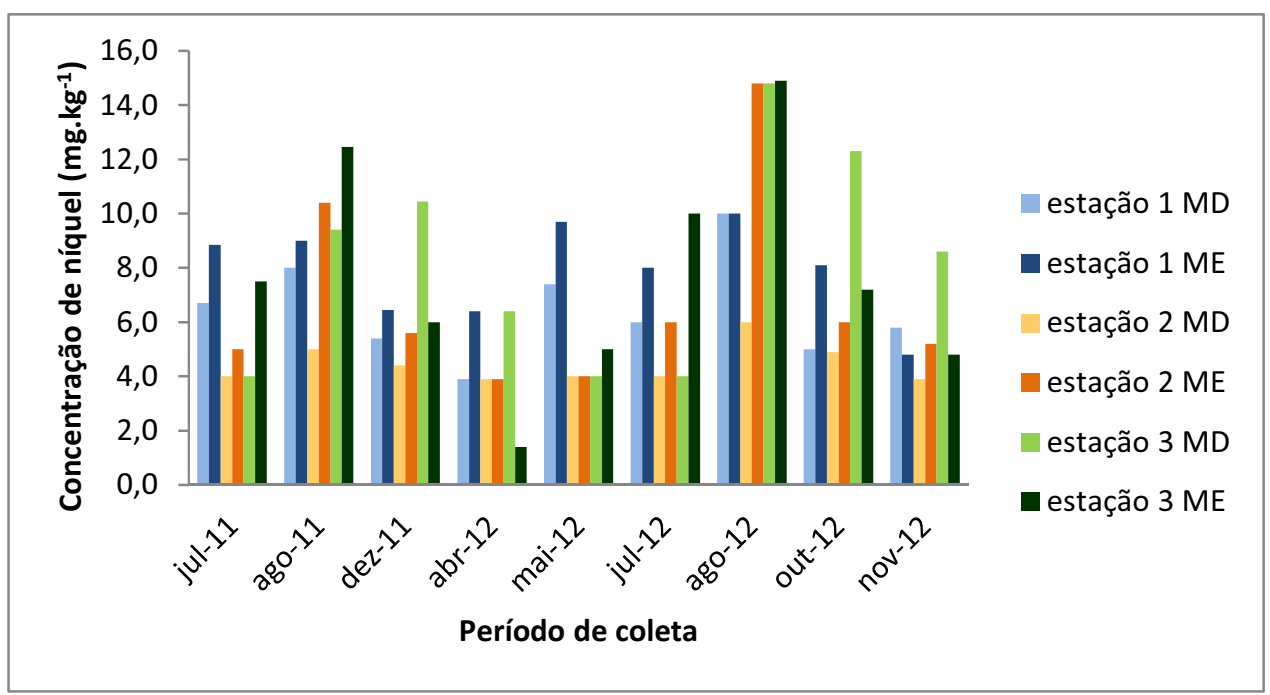

Figura 26 - Concentrações de níquel nos sedimentos coletados

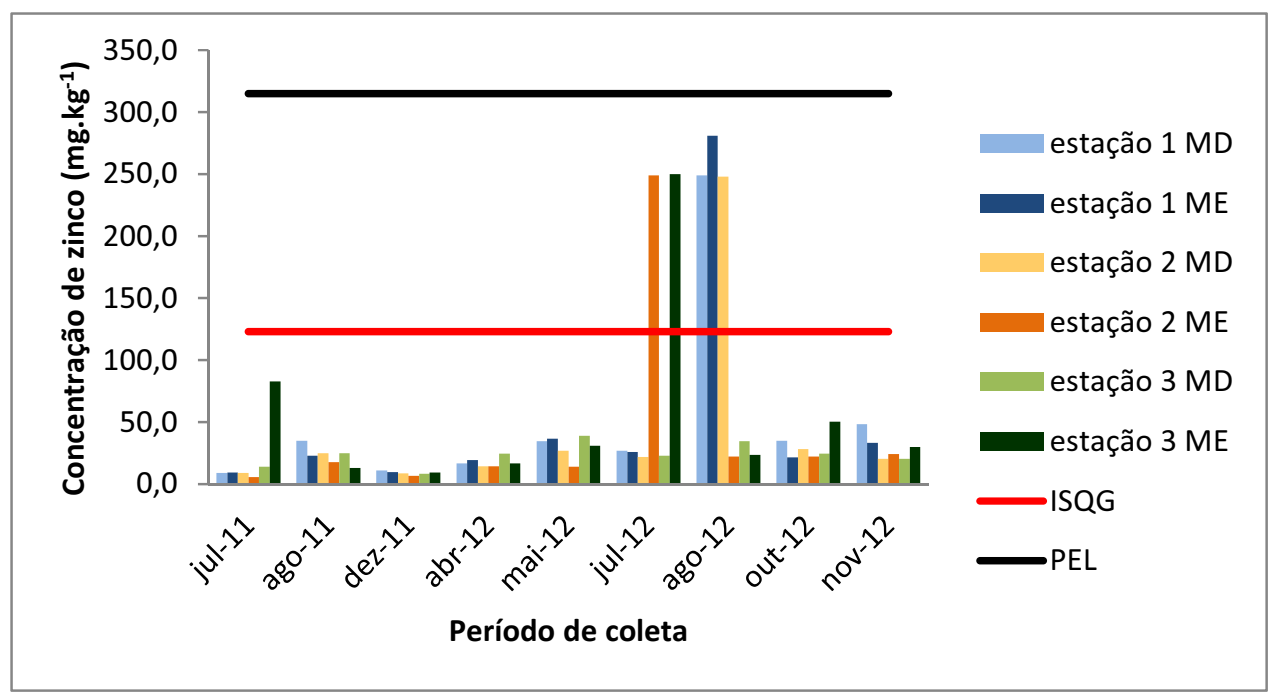

Figura 27 - Concentrações de zinco nos sedimentos coletados 


\section{DISCUSSÃO}

pH: A Resolução CONAMA n 357/2005 define para as classes de águas salobras, que o $\mathrm{pH}$ deve estar entre 6,5 e 8,5. Desta forma, é possível observar que os valores de $\mathrm{pH}$ encontrados no presente estudo estão de acordo com a referida resolução.

Resultados de $\mathrm{pH}$ encontrados por Silva (2010) em estações do estuário da Bacia do Pina (Região Metropolitana do Recife), corroboram com os resultados encontrados no presente estudo, visto que na Bacia do Pina a média do pH encontrado nas estações de coleta foi 7,3 .

Comparando os valores de $\mathrm{pH}$ encontrados no rio Maracaípe, com os valores descritos por Silva (2010) referentes ao estuário do Parque dos Manguezais e com os valores encontrados por Noronha (2008) no estuário do rio Timbó, observa-se que os mesmos são considerados normais para águas estuarinas.

Temperatura: Com relação à temperatura, é possível observar uma leve redução nos meses de Julho e Agosto de 2011 e 2012, provavelmente pela maior frequência de chuvas e menor influência da luz solar.

Segundo Passavante \& Feitosa (2004), a temperatura possui pouca variação em regiões tropicais.

$\mathrm{O}$ índice de variação térmica $\left(5,7^{\circ} \mathrm{C}\right)$ registrado neste trabalho foi baixo, característico de regiões estuarinas tropicais, bastante próximos dos valores registrados por Silva, 2004 e Noronha, 2008.

Salinidade: A salinidade é um parâmetro capaz de interferir na acumulação de metais em sedimentos, pois influencia diretamente no $\mathrm{pH}$ da água que, por sua vez, tem influência na disponibilidade de metais traço presentes nos sedimentos.

Smayda (1983) afirma que o fluxo e refluxo das marés, e a sazonalidade combinada às condições locais de precipitação, evaporação e descarga fluvial são elementos que provocam a diluição da água salgada na água doce, e consequentemente flutuações de salinidade nos estuários, geralmente mais baixa do que no mar adjacente.

Estudo realizado por Silva, 2010, em estuário tropical, demonstrou variação de salinidade semelhante $(1,2$ a 26,5$)$ à encontrada neste estudo, registrando influência da sazonalidade e da diluição da água salgada no estuário. Noronha (2008) avaliou a salinidade em pontos do rio Timbó, evidenciando influência da precipitação nos registros de baixas salinidades.

Oxigênio dissolvido: Os teores de oxigênio dissolvido encontrados, estão entre 5,08 mg.L-1 \pm 2,21 mg.L-1. É possível observar que os menores teores de oxigênio dissolvido e os maiores teores foram encontrados durante as estações seca e chuvosa, res- pectivamente, o que reforça a importância e influência da sazonalidade nestes resultados.

Observando o limite mínimo estabelecido na Resolução CONAMA n 357 de 2005 para águas salobras, é possível afirmar que o rio Maracaípe está de acordo com o que prevê a resolução para águas salobras de classe II em $70 \%$ das amostras avaliadas. Ainda é possível afirmar que dos $30 \%$ que não atendem à resolução, $89 \%$ foram de coletas em período seco (Dez/11, Out/12 e Nov/12).

Bastos et al. (2011) apontam registros de O.D., com uma variação de 3,7 a 7,37 mg.L-1. Como se trata do mesmo estuário (rio Maracaípe), verifica-se que com o passar dos anos, os teores mínimo e máximo mudaram, evidenciando que em alguns pontos o teor de O.D. aumentou e em outros ficou ainda mais crítico.

Noronha (2008) registrou no estuário do rio Timbó valores de O.D. variando entre $3,4 \mathrm{mg} . \mathrm{L}-1$ e 13,3 mg.L-1, evidenciando variação e valores semeIhantes aos do presente estudo.

Transparência: Macedo \& Costa (1990) ressaltam o papel do material em suspensão em ambientes estuarinos, reduzindo a penetração de radiação luminosa, bem como a influência da precipitação.

$\mathrm{Na}$ estação 2 foram registradas as menores transparências. Esta estação apresenta altos teores de M.O. e um fluxo de água mais dinâmico, contribuindo para uma menor transparência.

Bastos et al. (2011) observaram no estuário do rio Maracaípe, variações de transparência de $0,25 \mathrm{~m}$ a $2,7 \mathrm{~m}$, e assim como neste estudo, registraram menores transparências em período chuvoso, evidenciando a influência da precipitação e de material suspenso careado pela ação das chuvas.

Matéria orgânica: A estação 3 está localizada mais internamente no rio Maracaípe e portanto recebe maior influência da vasta vegetação de mangue existente no local, o que justifica um percentual mais alto de matéria orgânica na composição do sedimento lá encontrado. Já as estações 1 e 2 recebem menor influência da vegetação de mangue devido às suas localizações, que são, respectivamente, médio e baixo Maracaípe, estando a estação 1 ainda mais afastada do rio, e possuindo maior influência do ambiente marinho.

Marques et al. (2011) avaliou concentrações de matéria orgânica em sedimentos do estuário do rio Ipojuca, encontrando os maiores teores (15\%) em pontos onde a vegetação de mangue predomina, e os mais baixos teores (2\%) em estações onde a vegetação era reduzida, situação análoga à registrada neste estudo, evidenciando a influência da vegetação manguezal no teor de matéria orgânica dos sedimentos. Estes resultados reforçam a influência da vegetação das margens no teor de matéria orgânica, corroborando 
com o presente estudo.

Cádmio: Todas as concentrações de cádmio registradas nas estações 1, 2 e 3, ultrapassaram o limite ISQG. É possível observar que na estação 3 e na estação 1 foram encontradas as mais altas concentrações de cádmio (7,4 mg.kg-1 na estação 3 e 5,0 mg.kg-1 na estação 1), inclusive acima do valor PEL em todos os meses de período chuvoso.

As estações 1 e 3 encontram-se próximas à residências precárias construídas às margens do rio e à locais onde há grande influência de ação antrópica, respectivamente. A estação 1 está distante da confluência com o mar, porém, muito próxima de locais de lançamento de efluentes domésticos e resíduos da construção civil dispostos na própria margem. Já a estação 3 sofre influência da água salgada, por estar bastante próxima do mar. Esta estação também recebe impacto de quantidade considerável de turistas e pequenos bares instalados próximos à estação de coleta, bem como pequenas residências.

O cádmio é adsorvido mais facilmente aos sedimentos em ambientes com pH acima de 7,0 (Silva, 2002). Relacionando os resultados de $\mathrm{pH}$ encontrados nas estações 1 e 3 , principalmente, observa-se um $\mathrm{pH}$ variando entre $7,41 \pm 0,37$, respectivamente, o que reforça as altas concentrações de cádmio encontradas nestas estações.

Concentrações semelhantes às registradas neste estudo foram encontradas por Cotta, Rezende \& Piovani (2006) no estuário do rio Betari. As concentrações de Cd variaram entre 1,45 e 4,5 mg.kg-1 e portanto encontram-se também entre os limites de ISQG e PEL, e acima de PEL na estação 1 (mais alto do rio).

Huamao et al. (2012) avaliaram a concentração de $\mathrm{Cd}$ em sedimentos superficiais, registrando valores entre 0,06 e 1,54 mg.kg-1, ou seja, ultrapassando o valor de ISQG assim como todas as amostras de sedimento do presente estudo.

Os resultados registrados neste estudo evidenciam uma contaminação no ponto 3 , onde as concentrações ultrapassam o valor de PEL e portanto são esperados efeitos adversos.

Chumbo: O teor de chumbo no solo é muito influenciado por atividades antrópicas e pelo transporte do metal através do ar, oriundo de várias fontes. Tanto a deposição seca quanto a úmida são importantes vias de contaminação (World Health Organization, 1995).

$\mathrm{Na}$ análise de campo, nota-se a presença de elementos que possuem potencial para liberação do chumbo, como produtos químicos, embarcações, solda e emissão de efluentes domésticos. Além destes elementos, ao longo da margem direita do rio Maracaípe, existe uma rodovia onde há grande circulação de veículos, podendo contribuir para o incremento de chumbo nos sedimentos superficiais.

O chumbo foi avaliado e comparado com os respectivos valores de referência encontrados no "Sediment Quality Guideline" do CCME, que define ISQG de 35,0 mg.kg-1 e PEL de 91,3 mg.kg-1.

Verifica-se que nos meses chuvosos de 2012 (Julho e Agosto), ocorreu um pico de concentração do metal, nas estações 1 e 2, principalmente. Relacionando os parâmetros de pH (entre 7,0 e 8,0), transparência (entre $0,7 \mathrm{~m}$ e $1,30 \mathrm{~m}$ ) e salinidade (entre 13,7 e 19,0) no período, observa-se que estas condições hidrológicas contribuem para retenção deste metal no sedimento.

As concentrações encontradas estão muito acima do valor de PEL, o que evidencia uma grande probabilidade de interferência antrópica e eventual, já que apenas esses meses apresentaram concentrações tão elevadas do metal.

Troeh \& Thompson (2007) relatam que o $\mathrm{Pb}$ e outros metais pesados usados em combustíveis são dispersos na atmosfera e podem atingir áreas próximas aos locais de tráfego de veículos, sendo constatados incrementos na concentração de $\mathrm{Pb}$ e Cu em solos e plantas existentes ao longo das rodovias.

Huamao et al. (2012) registraram em sedimentos superficiais concentrações de $\mathrm{Pb}$ entre 6,2 e 39.3 mg.kg-1, tendo ultrapassado o limite ISQG apenas em uma estação (39,3 mg.kg-1), corroborando com a maior parte dos resultados registrados neste estudo, que somente ultrapassaram o ISQG em Dez/11 (apenas um ponto), Jul/12, Ago/12 e Out/12.

Quináia et al. (2009) avaliaram sedimentos superficiais em Guarapuava (PR), e registraram concentrações de $\mathrm{Pb}$ variando entre 7 e 320 mg.kg-1, sendo que aproximadamente $50 \%$ das amostras ultrapassaram o valor de ISQG, mas somente 2 amostras apresentaram concentrações acima do PEL, o que caracteriza semelhança com a distribuição do $\mathrm{Pb}$ nos sedimentos do estuário do rio Maracaípe.

Desta forma, é possível sugerir que a contaminação que atinge as estações avaliadas é uma combinação entre a presença de resíduos que possuem chumbo em sua composição e a relevância da sazonalidade, que em períodos chuvosos, promove a lixiviação do metal que se adere aos sedimentos.

Cobre: As concentrações de cobre encontradas nas análises dos sedimentos estão muito abaixo do ISQG definido pelo CCME, portanto, a concentração de cobre encontrada não representa uma ameaça ao ecossistema, no entanto, algumas informações devem ser pontuadas.

Visivelmente a estação 3, com exceção do mês de Abril/12, superou as outras estações com relação à concentração de cobre. Como podemos observar nas Figuras 4, 5, 6 e 8, a estação 3 fica mais próxima às 
residências construídas às margens do rio, onde os moradores despejam seu efluente doméstico.

Concentrações de cobre abaixo de 30,0 mg.kg-1 foram encontradas por Pedroso Neto (2011) em análise de sedimentos superficiais do rio Uberaba. Silva (2002) encontrou concentrações de até 49,0 mg.kg-1 ao avaliar sedimentos superficiais do rio MojiGuaçú. com os resultados encontrados neste trabalho nos sedimentos do rio Maracaípe.

Marques et al. (2011) avaliou a concentração de cobre em sedimentos do estuário do rio Ipojuca e encontrou uma variação entre 7 e 17 mg.kg-1 de Cu, bastante semelhante às concentrações registradas neste estudo.

Concentrações encontradas por Caldas e Sanches Filho (2013) na região de Laguna dos Patos, Pelotas, que variaram entre 5,1 mg.kg-1 e 12,2 mg.kg-1, corroboram com os resultados registrados neste estudo.

As concentrações encontradas nas estações 2 e 3 em Ago/11 e Jul/12, respectivamente, evidenciam uma relação entre a quantidade de M.O. encontrada nos sedimentos dessas estações e a adsorção dos metais a estes sedimentos.

Cromo: As mais altas concentrações de cromo foram registradas no período chuvoso (Ago/11, Jul/12 e Ago/12), coincidindo com um maior teor de matéria orgânica nos sedimentos, o que sugere a formação dos complexos e consequentemente maior adsorção aos sedimentos.

Silva (2010) registrou no Parque dos Manguezais concentrações de Cr entre 25 e 231 mg.kg-1, caracterizando um ambiente contaminado, diferente das concentrações encontradas no rio Maracaípe que não caracterizam ambiente contaminado.

Marques et al. (2011) registrou concentrações de $\mathrm{Cr}$ em sedimentos do estuário do rio Ipojuca variando entre 17 e $36 \mathrm{mg} . \mathrm{kg}-1$, caracterizando sedimentos não poluídos, corroborando com os resultados encontrados no presente estudo.

Ferro: Nos meses de chuva (Maio, Julho e Agosto) é possível notar uma maior concentração de ferro encontrada nas amostras de sedimento, inclusive ultrapassando o limite EPA, o que ocorre provavelmente por efeito das condições pluviométricas no período de coleta, que facilita a mobilização dos metais. No mesmo período, a salinidade se manteve relativamente alta, o que contribui para a adesão dos metais aos sedimentos, e o pH entre neutro e alcalino que também justifica a alta concentração do metal nos referidos meses. O teor de matéria orgânica foi também mais elevado nos períodos de chuva, o que é bem provável tenha contribuído para a alta concentração de metais em geral, principalmente o ferro, neste período.
Não foi possivel atribuir uma correlação entre as estações, com algumas exceções, como na estação $1 \mathrm{ME}$ em Agosto/12 e na estação $2 \mathrm{MD}$ em abril/12, que seguem uma homogeneidade durante todo o período de coletas. Esta informação sugere impacto regional e não pontual ou local, visto que os estações se distanciam bastante umas das outras.

Alguns trabalhos corroboram com os resultados de ferro encontrados, como por exemplo, Silva (2010) que encontrou altas concentrações de ferro em período chuvoso em avaliação realizada no Parque dos Manguezais (PE), e Silva (2002) que encontrou concentrações acima de 17000 mg.kg-1 em várias estações de coleta em Junho/01, no rio Moji-Guaçu (SP).

Manganês: O manganês é um metal que não possui valores de referência específicos descritos por agências nacionais ou internacionais do meio ambiente, e por este motivo, o valor utilizado como background para avaliação deste metal foi a concentração de 160 mg.kg-1 de Mn, encontrada em área protegida pela marinha, conhecida como a antiga Estação de Rádio da Marinha no Parque dos Manguezais/PE (080 05' 58,4"S/340 53' 35,01" W).

Em nenhuma das estações avaliadas obteve-se uma concentração acima ou sequer próxima do valor de background utilizado (160 mg.kg-1). É possível observar uma grande diferença entre a estação 1 , e as estações 2 e 3 . Esta diferença ocorre pelo fato de a estação 1 sofrer ação direta e contínua de visitação de turistas, e contar com a instalação de pequenos bares, que comercializam produtos diversos, sugerindo uma maior poluição.

Estudos recentes, como os publicados por Silva (2010) e Pedroso Neto (2011), apontam concentrações de manganês mais altas do que o valor ora utilizado como background neste trabalho, evidenciando que no Parque dos Manguezais e no rio Uberaba ocorre uma contaminação de manganês.

Brayner e Matvienko (2003) concluíram que tanto o manganês quanto o ferro na forma divalente são mais solúveis que em sua forma trivalente e podem ser liberados do sedimento para coluna d'água, realizando o transporte de oxigênio dissolvido para os ambientes anóxicos, devido as constantes trocas com a coluna d'água.

As concentrações de manganês registradas nos sedimentos avaliados no estuário do rio Maracaípe apontam para uma não contaminação, além de terem sido muito menores do que o background utilizado. Desta forma, é possível que as concentrações encontradas neste estudo possam ser utilizadas como background em novos estudos de áreas estuarinas tropicais.

Níquel: A justificativa de análise do metal traço neste trabalho está na contribuição antrópica que 
atinge o local e que possui potencial para elevar as concentrações de níquel nos sedimentos. Nas áreas adjacentes ao rio Maracaípe é possível observar a presença de muitas embarcações cuja solda utilizada é rica em níquel, e também muitas oficinas, que são potenciais geradoras de resíduo rico em níquel. Como as margens, principalmente a direita do rio Maracaípe, possuem todo tipo de construção, esperava-se encontrar concentrações razoáveis do metal nas estações selecionadas.

Como o níquel é geralmente transportado através de lixiviação, é provável que esse seja o motivo de concentrações majoritariamente mais altas do metal nos meses de maior precipitação (Julho e Agosto).

Estudo realizado em 2008 na Pontifícia Universidade Católica - RJ, demonstra concentrações menores de níquel (entre 3,5 mg.kg-1 e 9,4 mg.kg-1), se comparadas às obtidas no presente estudo, o que pode representar uma leve contaminação nos sedimentos do rio Maracaípe. Outro estudo que corrobora com esta informação é o realizado em 2011 por Pedroso Neto, que também encontrou concentrações de níquel abaixo de 4,0 mg.kg-1, bem abaixo das concentrações encontradas neste estudo.

Ainda no estudo realizado por Pedroso Neto, em 2011, descreve-se um valor de referência para o níquel, definido pela Companhia Ambiental do Estado de São Paulo, de até 13 mg.kg-1, para considerar um sedimento normal, sem potencial poluidor. Se comparadas ao valor de referência citado, as concentrações de níquel estão de fato um pouco acima, pelo menos nos períodos de chuva, do que o sugerido pela Companhia Ambiental do Estado de São Paulo.

Zinco: Dentre os íons metálicos, o Zinco (Zn) possui características relevantes quando se trata de impactos ambientais, pois estão presentes em fertilizantes e pesticidas, bem como nos resíduos orgânicos provenientes dos perímetros urbanos (Ramalho et al., 2000; Linnik \& Zubenko, 2000; Besser et al., 2007).

Os resultados das análises das concentrações de zinco evidenciam uma grande contribuição no período chuvoso em 2012, visto que as concentrações encontradas neste período ultrapassam o limite ISQG, definido pelo CCME. Já as concentrações nos períodos secos estão bem abaixo do valor ISQG. As concentrações variaram entre 5,9 mg.kg-1 e 281,0 mg.kg-1, o que representa a relevância da sazonalidade para este metal.

$O$ fato de serem observadas concentrações acima do ISQG somente em dois meses de coleta sugere uma contribuição pontual, provavelmente do período de manutenção das embarcações, que está compreendido entre Junho e Agosto (período de férias escolares), haja vista a regularidade da concentração nos demais meses e a quantidade de barcos de turismo que circulam no estuário durante o período citado.

Silva (2010) descreveu influência da sazonalidade nas concentrações de zinco nos sedimentos de Estações do Parque dos Manguezais, onde as mais altas concentrações ocorreram, assim como neste estudo, no período chuvoso.

Assim como no presente estudo, Cotta, Rezende \& Piovani (2006) registraram valores abaixo do ISQG e entre ISQG e PEL para zinco no estuário do rio Betari em diferentes estações. Belo, Quináia \& Pletsch (2010) avaliaram o teor de zinco em sedimentos do Lago de Itaipu e registraram concentrações entre 18,4 e 109 mg.kg-1, ou seja, abaixo do limite ISQG e portanto, corroborando com $90 \%$ dos resultados obtidos no presente estudo que também estão abaixo do ISQG.

\section{CONCLUSÕES}

Diante dos resultados apresentados, pode-se concluir que o cromo, o cobre e o manganês não representam ameaça de contaminação à matriz sedimento do estuário do rio Maracaípe. Chumbo, ferro, cádmio e zinco apresentaram concentrações elevadas e acima dos valores definidos pelas legislações internacionais utilizadas para comparação, portanto, evidenciando uma contaminação dos sedimentos das estações.

As concentrações dos metais traço chumbo, cobre, ferro, cromo, níquel e zinco encontradas neste estudo revelam uma influência relevante da sazonalidade, indicando influência da precipitação na adsorção dos metais aos sedimentos.

As concentrações de manganês registradas neste estudo representam novas concentrações de background que podem ser utilizadas por futuros estudos semelhantes, ou seja, em áreas estuarinas tropicais.

Considerando as concentrações da maioria dos metais ( $\mathrm{Cd}, \mathrm{Cu}, \mathrm{Cr}, \mathrm{F}, \mathrm{Ni})$ na estação 3, pode-se concluir que os sedimentos da mesma são os mais contaminados.

\section{REFERÊNCIAS}

American Public Health Association (APHA). 2012. Standard Methods for the Examination of Water and Wastewater. 22nd ed. American Public Health Association, Washington (DC).1100p.

Baird, C. 2002. Química Ambiental. 2a Edição. Bookman, Porto Alegre. 622p.

Bastos, R.B. et al. 2011. Caracterização de uma zona costeira tropical (Ipojuca-Pernambuco-Brasil): 
Produtividade Fitoplanctônica e outras variáveis ambientais. Braz. J. Aq. Sci. and Tech. 15(1): 1-10.

Besser, J.M. et al. 2007. Biomonitoring of lead, zinc, and cadmium in streams draining lead-mining and nonmining areas, Southeast Missouri, USA. Environ. Monit. Assess., 129 (1): 227-241.

Brayner, F.M.M. \& Matvienko, B. 2003. Manganese and iron as oxygen carriers to anoxie estuarine sediment. Journal de Physique, 107(1): 22-232.

Belo, A.; Quináia, S.P. \& Pletsch, A.L. 2010. Avaliação da contaminação de metais em sedimentos superficiais das praias do lago de Itaipú. Química nova, 33(3): 613-617.

Caldas, J.S. \& Sanches Filho, P.J. 2013. Determinação de $\mathrm{Cu}, \mathrm{Pb}$ e $\mathrm{Zn}$ no sedimento da Região do pontal da Barra, Laranjal (Laguna dos patos, Pelotas - RS/BRASIL). Braz. J. Aq. Sci. And Tech., 17(1):13-18.

Cotta, J. A. O.; Rezende, M.O.O.; Piovani, M.R. 2006. Avaliação do teor de metais em sedimento do rio Betari no Parque Estadual Turístico do Alto do Ribeira - Petar, SP. Química Nova. 29 (1): 40-45.

Drummond, C. \& Israelachvili, J. 2004. Fundamental studies of crude oil-surface water interactions and its relationship to reservoir wettability. Journal Petroleum Sci Engineering, 45(1): 61-81.

Empresa Brasileira de Pesquisa Agropecuária (EMBRAPA). 1997. Manual de métodos de análise de solos. 2a Edição. Embrapa Solos, Rio de Janeiro. $212 p$.

Huamao, Y. et al. 2012. Distribution and contamination of heavy metals in surface sediments of the south Yellow Sea. Marine Pollution Bulletin, v.64(1): p.2151-2159.

Institute of Oceanography of Great Britain. 1973. International Oceanographic Tables. UNESCO, Paris. $141 \mathrm{p}$.

Linnik, P.M. \& Zubenko, I.B. 2000. Role of bottom sediments in the secondary pollution of aquatic environments by heavy-metal compounds. Lakes \& Reservoirs: Research and Management. 5(1): 11-21.

Luiz-Silva, W. et al. 2006. Variabilidade espacial e sazonal da concentração de Elementos-traço em sedimentos do sistema estuarino de SantosCubatão (SP). Química Nova, 29(2): 256-263.

Macedo, S.J. \& Costa, K.M.P. 1990. Condições hidrológicas do estuário do rio Igarassu-Itamaracá - PE. Trabalhos Oceanográficos, 21(1): 7-32.

Marques, J.S.J. et al. 2011. Geoquímica de metais em sedimentos da zona estuarina do complexo industrial Porto de Suape, PE - BRASIL. Revista de Gestão Costeira Integrada. v.11(1): 379-387.
Noronha, T.J.M. 2008. Avaliação das concentrações de metais pesados em sedimentos do estuário do rio Timbó, Pernambuco-Brasil. Dissertação de Mestrado. Instituto de Tecnologia de Pernambuco. $101 \mathrm{f}$.

Passavante, J.Z.O. \& Feitosa, F.A.N. 2004. Dinâmica da produtividade fitoplanctônica na zona costeira marinha. In: Eskinazi-Leça E.; Neumann-Leitão, S.; Costa, M. F. (Ed.) Oceanografia: Um cenário tropical. Bagaço. 425-439pp.

Pedroso Neto, J.C. 2011. Quantificação de metais pesados na bacia hidrográfica do rio Uberaba. Revista FAZU, 8(1): 40-46.

Prieto, A. et al. 2008. Levels and spatial distribution of inorganic and organic contaminants in sediments along the Bilbao estuary. Marine Pollution Bulletin, 12 (56): 2094-2099.

Quináia, S.P.; Cavagnoli, A.R. \& Martins, V.J. 2009. Avaliação da Distribuição de $\mathrm{Cr}, \mathrm{Pb}$ e $\mathrm{Cu}$ em Sedimentos Superficiais. Revista Ciências Exatas e Naturais, 11(1): 50-66.

Ramalho, J.F.G.P. et al. 2000. Contaminação da microbacia de Caetés com metais pesados pelo uso de agroquímicos. Pesq. Agropecu. Bras. 35(7): 1289-1303.

Silva, C. A. R. 1998. Distribuição e ciclagem interna de metais pesados em um

ecossistema de manguezal combinado com Rhizophora mangle, Baía de

Sepetiba, Rio de Janeiro. Niterói. Dissertação (Mestrado), Universidade Federal Fluminense.

Silva, H. K. P. 2004. Concentração de metais pesados nos sedimentos do estuário do Rio Capibaribe, na Região Metropolitana do Recife (RMR) Pernambuco, Brasil. Dissertação de Mestrado. Departamento de Oceanografia, Universidade Federal de Pernambuco. 129p.

Silva, H. K. P. 2010. Avaliação das concentrações de metais traço e suas interações nos sedimentos e biota do parque dos manguezais, região metropolitana do recife (RMR), Pernambuco, Brasil. Tese de Doutorado. Departamento de Oceanografia, Universidade Federal de Pernambuco. $150 \mathrm{f}$.

Silva, M. R. C. 2002. Estudo de sedimentos da bacia hidrográfica do rio Moji-Guaçu, com ênfase na determinação de metais. Dissertação de Mestrado. Universidade de São Paulo. 113p.

Smayda, T.J. 1983. The phytoplancton of estuaries. In: KETCHUM, B.H. Estuaries and enclosed seas. Elsevier, 65-102pp.

Tam, N. F. Y. \& Wong, W. S. 2000. Spatial variation of heavy metals in surface sediments of Hong Kong mangrove swamps. Environmental Pollution, 110(1):195-205. 
COIMBRA, C.D., et al. (2015). Metais traço no rio Maracaípe em 2011 e 2012.

Troeh, F. R. \& Thompson, L. M. 2007. Soils and soil fertility. $6^{\text {a }}$ Edição. Blackwell Publishing Ltda., Oxford, 718p

Vila Nova, F. V. P.; Allgayer, M. \& Campos, H. L. 2009. Práticas Contraditórias entre a Legislação Ambiental e o Turismo no Estuário do Rio Maracaípe: estudo de caso. In: MARCOS ROBERTO NUNES COSTA. (Org.). Gestão Integrada de Ambientes Costeiros e Impactos Ambientais. 1: 223-230.
Vila Nova, F. V. P. \& Torres, M. F. A. 2012. Avaliação ambiental em unidades de conservação: Estuário do rio Maracaípe, Ipojuca-PE, Brasil. Revista de Geografia, 29(3): 199-224.

World Health Organization. 2004. Manganese and its compounds: Environmental aspects. World Health Organization, Geneva. 70p.

Submetido: Setembro/2013

Revisado: Janeiro/2014

Aceito: Março/2014 